\title{
The SPACE Computer Code for Analyzing the International Space Station Electrical Power System: Past, Present, and Future
}

\author{
Sara G. Miller ${ }^{1}$, Brandon T. Klefman ${ }^{2}$, Steven Korn², \\ Terrian V. Nowden'2, Ann M. Delleur ${ }^{3}$, and David B. McKissock ${ }^{2}$ \\ National Aeronautics and Space Administration, Glenn Research Center, Cleveland, Ohio 44135
}

\begin{abstract}
The System Power Analysis for Capability Evaluation (SPACE) computer code was initially developed by NASA in 1988 to assess the Space Station Freedom electric power system $^{1,2}$ and later adapted to support contractor electrical power system capability analyses for the International Space Station (ISS). Over time, the code has supported many efforts such as ISS redesign activities in the early 1990s, assessment of time-phased loads against power system operating limits for future ISS assembly flights (including Certification of Flight Readiness reviews by the ISS program office), and determining the optimum solar array gimbal positions while respecting keep-out zones which minimize both solar array contamination and structural loads. The code has been validated by comparisons with ISS onorbit data in multiple validation episodes. Recent updates to the code include the incorporation of a Lithium-Ion battery model in addition to the nickel-hydrogen battery model and modifications to the solar array degradation model to better match on-orbit test results. SPACE has also been extended beyond the ISS to include modeling of the Orion MultiPurpose Crew Vehicle electrical power system (SPACE-MPCV) and Mars Surface Electrical Power Systems (MSEPS). Portions of SPACE were integrated with a trajectory code to form a Solar Electric Propulsion Simulation (SEPSim), which can be used for analyzing solar electric propulsion missions. In addition, SPACE methods and subroutines have been adapted to a multitude of other projects ${ }^{3-7}$. This paper summarizes the initial code development and subsequent code utilization in the context of the overall ISS program development and onorbit operations. Recent updates and results from the code are discussed, including preliminary analyses for the Orion power system.
\end{abstract}

\section{Nomenclature}

$\begin{array}{ll}\text { ARCU } & =\text { American-Russian Converter Unit } \\ B C D U & =\text { Battery Charge Discharge Unit } \\ B G A & =\text { Beta Gimbal Assembly } \\ C o F R & =\text { Certification of Flight Readiness } \\ D C S U & =\text { DC-DC Switching Unit } \\ D D C U & =\text { DC-DC Converter Unit } \\ D E N I & =\text { Damage Equivalent Normally Incident } \\ D O D & =\text { Depth of Discharge } \\ E O C V & =\text { End of Charge Voltage } \\ E P S & =\text { Electrical Power System } \\ E V A & =\text { Extravehicular Activity } \\ G O E S & =\text { Geostationary Operational Environmental Satellite } \\ G R C & =\text { Glenn Research Center }\end{array}$

${ }^{1}$ Graduate Student, Georgia Institute of Technology; Pathways Intern, Power Architecture and Analysis Branch, AIAA Student Member.

${ }^{2}$ Electrical Power Systems Engineer, Power Architecture and Analysis Branch.

${ }^{3}$ Electrical Power Systems Engineer, Power Architecture and Analysis Branch, AIAA Senior Member. 


$\begin{array}{ll}\text { ISS } & =\text { International Space Station } \\ \text { JSC } & =\text { Johnson Space Center } \\ \text { Li-ion } & =\text { Lithium-Ion } \\ M B S U & =\text { Main Bus Switching Unit } \\ M E T & =\text { Mission Elapsed Time } \\ M M O D & =\text { Micrometeoroid and Orbital Debris } \\ M P C V & =\text { Multi-Purpose Crew Vehicle } \\ M S E P S & =\text { Mars Surface Electrical Power Systems } \\ \text { NiH } & =\text { Nickel-Hydrogen } \\ \text { ORU } & =\text { Orbital Replacement Unit } \\ \text { Pmax } & =\text { Solar cell maximum power } \\ \text { SARJ } & =\text { Solar Alpha Rotary Joint } \\ \text { SEPSim } & =\text { Solar Electric Propulsion Simulation } \\ \text { SOC } & =\text { State of Charge } \\ \text { SPACE } & =\text { System Power Analysis for Capability Evaluation } \\ \text { SSU } & =\text { Sequential Shunt Unit } \\ \text { STS } & =\text { Space Transportation System } \\ \text { VAC } & =\text { Verification Analysis Cycles }\end{array}$

\section{Introduction}

$\mathrm{T}$

HE SPACE computer model was developed to predict the performance of the International Space Station (ISS)

Electrical Power System (EPS). SPACE analyzes and predicts the power generation capacity of the ISS EPS, as well as its current state, as a function of ISS attitude, solar array pointing, and orbital conditions. SPACE integrates orbital mechanics, solar array pointing/shadowing/electrical/thermal, battery, and power management and distribution modules into a cohesive tool that can output minute-by-minute EPS performance predictions. The flexible architecture of the tool allows for both power generation and load-driven models. In the power generation case, SPACE ensures that energy balance is maintained without violating EPS hardware, software, and operational constraints. In a loaddriven scenario, SPACE determines whether a given electrical load profile can be supported by the power system.

The ISS contains the largest and most complex EPS ever assembled and operated in orbit. Each ISS solar array wing is tied to a single power channel for a total of eight power channels. Four hundred solar cells connected in series form a string and the ISS EPS contains 82 strings. The ISS EPS architecture for a single power channel, prior to recent battery upgrades, is shown in Fig. 1. During insolation periods, power from the solar array flows to the Sequential Shunt Unit (SSU). The SSU shunts unneeded solar array strings to regulate the primary bus voltage. Power then flows through the Beta Gimbal Assembly (BGA), which rotates the solar array to adjust for the seasonal solar beta angle, or the angle measured between the solar vector (incident sunlight) and the orbit plane. Solar array power then enters the DC Switching Unit (DCSU) and flows into the Battery Charge Discharge Unit (BCDU) to charge batteries and/or flows downstream through the Solar Alpha Rotary Joint (SARJ) and the Main Bus Switching Unit (MBSU) to either the DC-DC Converter Units (DDCUs) or the American-Russian Converter Unit (ARCU). The DDCUs convert from the primary bus voltage (nominally $160 \mathrm{~V}$ ) to the secondary distribution voltage (nominally $120 \mathrm{~V}$ ).

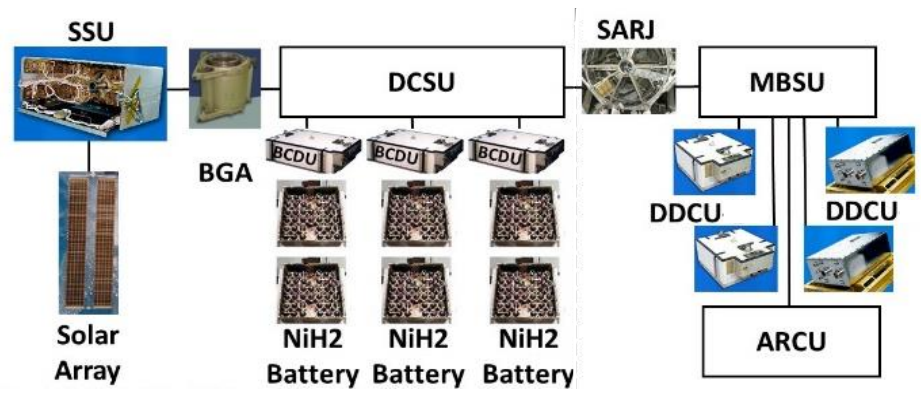

Figure 1. ISS EPS channel architecture. 
During the eclipse portion of an orbit, the nickel-hydrogen $\left(\mathrm{NiH}_{2}\right)$ batteries discharge with the power flowing through the BCDU. The BCDU raises the battery voltage to the primary bus voltage. There are three BCDUs on each power channel, with each BCDU fed by two $\mathrm{NiH}_{2}$ battery Orbital Replacement Units (ORUs) in series. Two $\mathrm{NiH}_{2}$ battery ORUs together make one ISS battery. The power then flows through the DCSU to the SARJ and into the MBSU. A small amount of power flows from the DCSU back through the BGA to provide keep-alive power to the SSU.

The ISS is shown in Fig. 2 with all eight U.S. power channels installed. The ISS power channel name is shown in white text next to each solar array, while the truss segments are labeled in red. This picture was taken in May 2011, slightly more than two years after the last power module was installed in March 2009.

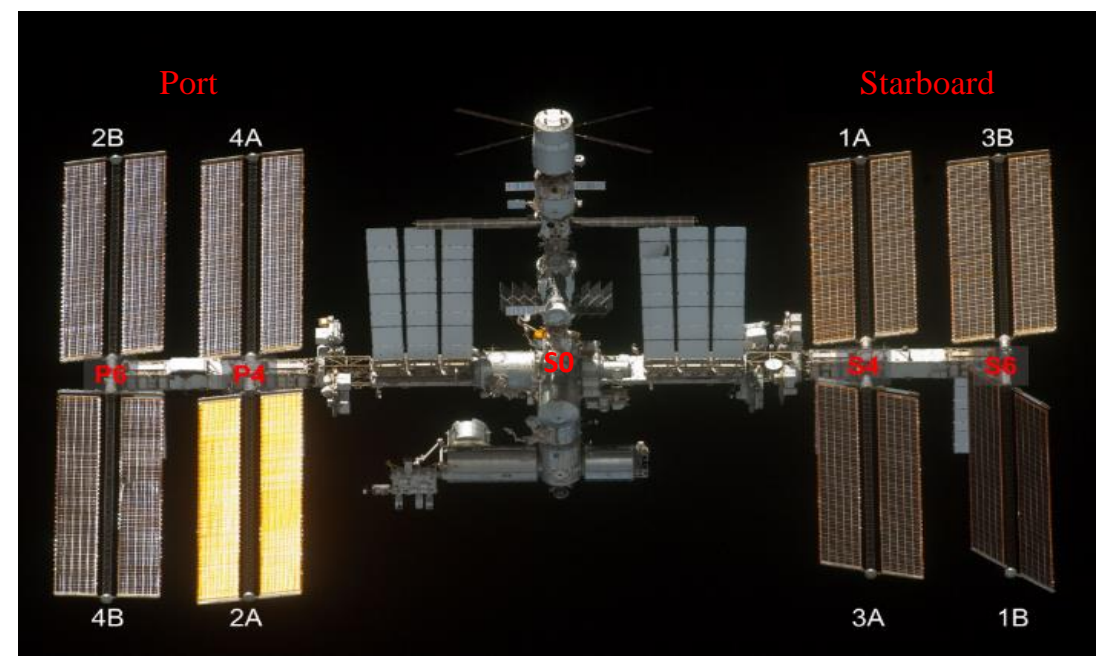

Figure 2. ISS EPS channels and truss segments (S134-E-011548, May 29, 2011).

The key ISS EPS assembly flights are described in Table 1. Both the Space Transportation System (STS) flight designation and the ISS program designation are shown in the first column.

Table 1 Key ISS EPS Assembly Flights

\begin{tabular}{|l|l|l|}
\hline Flight & Date & Description \\
\hline $\begin{array}{l}\text { STS-97 } \\
\text { 4A }\end{array}$ & $12 / 2000$ & $\begin{array}{l}\text { P6 (2B/4B) launched and } \\
\text { installed }\end{array}$ \\
\hline $\begin{array}{l}\text { STS-98 } \\
\text { 5A }\end{array}$ & $2 / 2001$ & $\begin{array}{l}\text { U.S. Destiny Laboratory } \\
\text { added, with 6 DDCUs }\end{array}$ \\
\hline $\begin{array}{l}\text { STS-110 } \\
8 \text { A }\end{array}$ & $4 / 2002$ & $\begin{array}{l}\text { S0 truss launched with MBSUs } \\
\text { and 4 DDCUs. MBSUs were } \\
\text { dormant until the EPS } \\
\text { reconfiguration in 2006 }\end{array}$ \\
\hline $\begin{array}{l}\text { STS-115 } \\
12 A\end{array}$ & $9 / 2006$ & P4 (2A/4A) launched \\
\hline $\begin{array}{l}\text { STS-116 } \\
12 A .1\end{array}$ & $12 / 2006$ & $\begin{array}{l}\text { EPS reconfigured to use } \\
\text { MBSUs, retract 4B solar array }\end{array}$ \\
\hline $\begin{array}{l}\text { STS-117 } \\
13 A\end{array}$ & $6 / 2007$ & $\begin{array}{l}\text { S4 (1A/3A) launched, retract } \\
\text { 2B solar array }\end{array}$ \\
\hline $\begin{array}{l}\text { STS-120 } \\
\text { 10A }\end{array}$ & $10 / 2007$ & $\begin{array}{l}\text { Eight DDCUs launched with } \\
\text { Node 2 (Harmony). Redeploy } \\
\text { 2B/4B solar arrays }\end{array}$ \\
\hline $\begin{array}{l}\text { STS-119 } \\
15 A\end{array}$ & $3 / 2009$ & S6 (1B/3B) launched \\
\hline $\begin{array}{l}\text { STS-127 } \\
\text { 2J/A }\end{array}$ & $7 / 2009$ & 2B NiH battery replacement \\
\hline
\end{tabular}




\begin{tabular}{|l|l|l|}
\hline Flight & Date & Description \\
\hline $\begin{array}{l}\text { STS-132 } \\
\text { ULF4 }\end{array}$ & $5 / 2010$ & 4B NiH battery replacement \\
\hline HTV6 & $12 / 2016$ & $\begin{array}{l}\mathrm{NiH}_{2} \text { batteries on 1A/3A } \\
\text { replaced with Li-ion }\end{array}$ \\
\hline
\end{tabular}

The ISS typically orbits in the Xvv Znadir flight attitude, where the $+\mathrm{X}$-axis is aligned with the orbital velocity vector and the $+Z$-axis points nadir. Historically, the ISS has also flown in the XPOP attitude due to power and thermal constraints during the early Space Station configurations ${ }^{8}$. In the XPOP attitude, the ISS $+\mathrm{X}$-axis is perpendicular to the orbit plane. Following assembly flight STS-115 12A, however, the XPOP attitude is no longer available after the thermal control system was filled with ammonia. The complexity of ISS assembly and operations called for a computer model that could account for all the changes in architecture, attitude, and other important effects. This was the driving force behind the development of SPACE.

\section{Legacy SPACE Results}

Perhaps the most complex ISS assembly operation was the retraction of the 4B solar array, installation of truss segment P5, and additional EPS reconfigurations on Flight 12A.1, launched in December 2006. NASA Glenn Research Center (GRC) staff performed a detailed analysis for this flight using SPACE, while the ISS Program worked to develop a scenario that would successfully assemble the station. An assessment from 2002, summarized in Figure 3, provided an option for Flight 12.1A operations. The space shuttle launches at Mission Elapsed Time (MET) 0.0. There are five rows of graphs shown in Fig. 3.

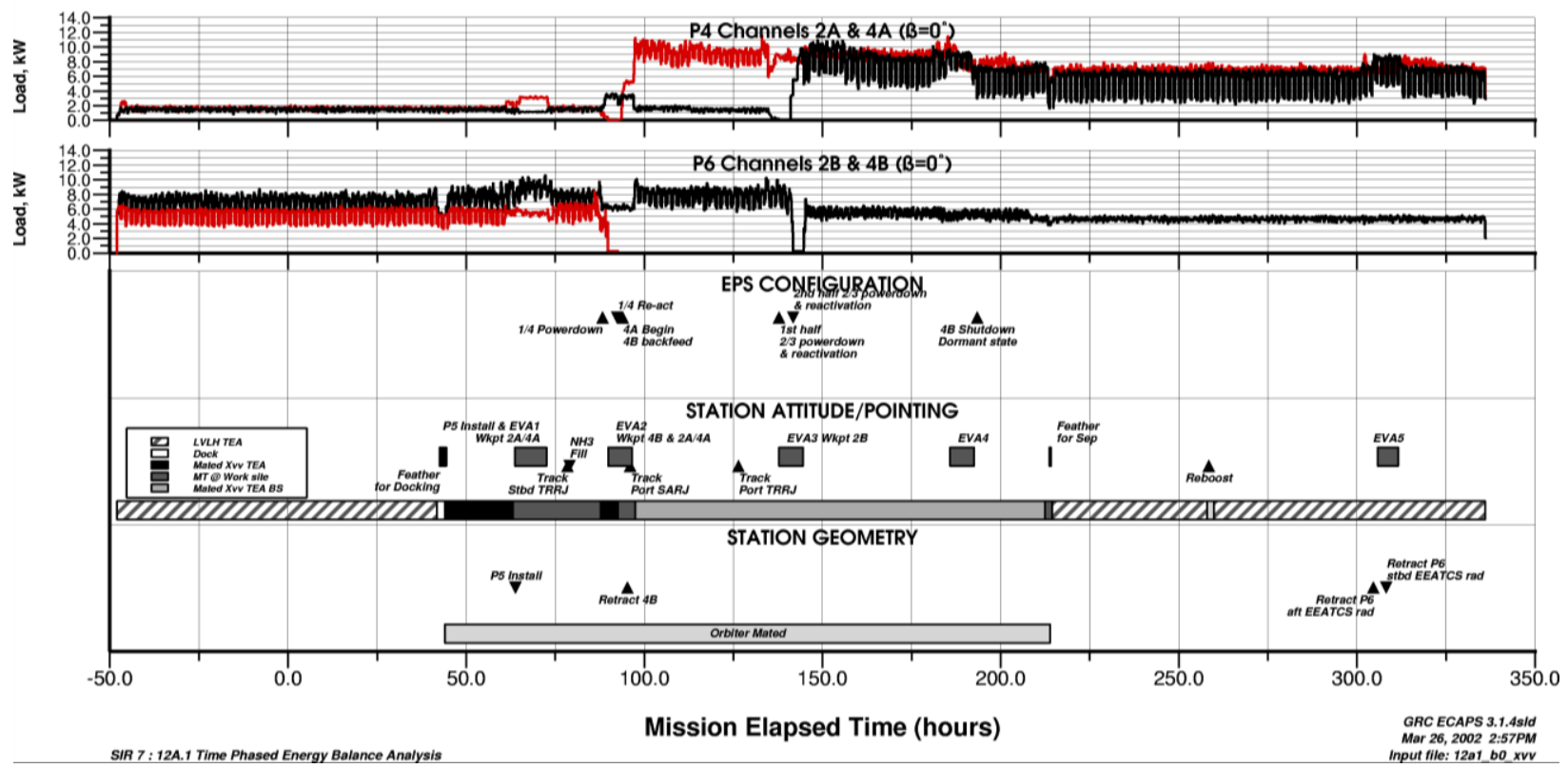

Figure 3. Flight 12A.1 summary timeline from 2002.

- The fifth row, "Station Geometry", shows where the geometric configuration of the ISS changes. Near MET 40 hours, the space shuttle orbiter docks to the ISS and must be accounted for. The black triangles show four other modifications to the ISS geometry during the mission. Each unique ISS geometry is modeled in SPACE at the times shown in Fig. 3.

- The fourth row, "Station Attitude/Pointing", shows the ISS attitude and solar array pointing conditions. There are five different ISS attitudes during the mission, each modeled in SPACE. The solar arrays are held fixed during docking and separation. The gimbals, which normally rotate the solar arrays to track the sun, are parked for long periods of time to allow for installation of a new truss segment and to facilitate moving 
a pair of solar array wings from one part of the ISS to another. The solar arrays are wake pointed during some Extravehicular Activities (EVAs) to minimize shock hazards to the crew.

- The third row, "EPS Configuration", shows the EPS configuration, while the top two rows, "P4 Channels $2 \mathrm{~A} \& 4 \mathrm{~A}\left(\beta=0^{\circ}\right)$ " and "P6 Channels $2 \mathrm{~B} \& 4 \mathrm{~B}\left(\beta=0^{\circ}\right)$ ", show the load demand on the P4 and P6 power channels respectively. At the beginning of Flight 12A.1, there were four operating power channels. These power channels were not using the MBSUs that were launched in 2002. Rewiring the ISS to use the MBSUs required shutting down some power channels. The first reconfiguration happens around MET 85 hours, with power channels $4 \mathrm{~A}$ and $4 \mathrm{~B}$ shut down. The load demand on both these power channels goes to zero during the reconfiguration. After this reconfiguration was completed, the 4B solar array was retracted. This is noted in the fifth row showing ISS geometry (Retract 4B), the fourth row showing ISS attitude/pointing (Track Port SARJ), the third row showing EPS configuration (4A Begin 4B backfeed), and in the second row where the $4 \mathrm{~B}$ power demand is terminated. Power channels 2A and 2B were reconfigured around MET 135 hours.

SPACE predictions from 2002, proposed Flight 12.1A scenario, for the first EVA on this mission, EVA \#1, installs truss segment P5 as shown in Fig. 4. The power channel 2A solar array is edge-on to the sun during EVA \#1 such that it is producing no power and the load demand is high enough to cause the batteries to become completely discharged. This situation was unacceptable, so a series of additional analyses were performed to identify procedures that would avoid draining the batteries.

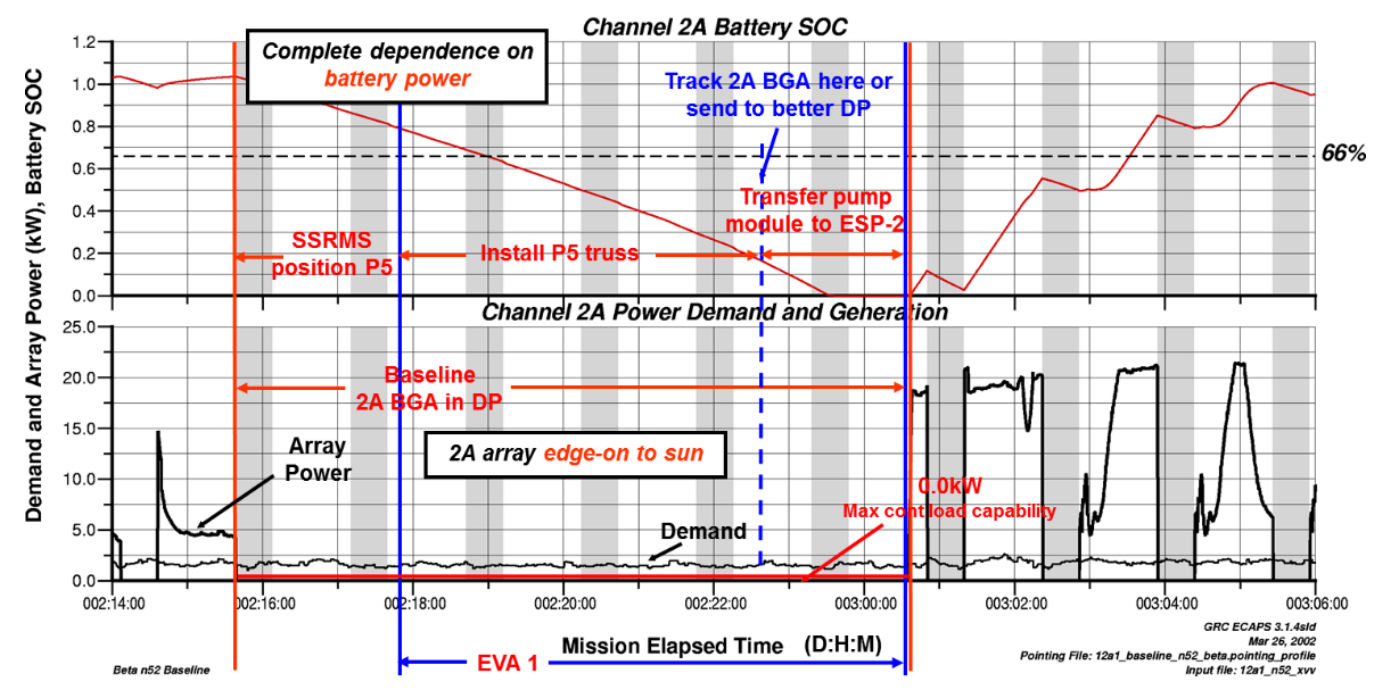

\section{Figure 4. Channel 2A load demand, solar array power, and battery SOC during EVA \#1} with $P 5$ installation on Flight 12A.1, solar beta $-52^{\circ}$.

Another example of SPACE results for Flight 12.1A is shown in Fig. 5, which shows the MBSU reconfiguration during EVA \#3 at solar beta $0.0^{\circ}$. The power channel $4 \mathrm{~A}$ battery state of charge (SOC) stays above the $66 \%$ guideline, while the $2 \mathrm{~A}$ battery SOC goes to zero using a strategy of shunting the solar array power until noon (green line). It should be noted that an SOC of zero corresponds to an empty battery, whereas an SOC of one corresponds to a fullycharged state. Results with two alternative solar array shunting strategies are also shown for comparison.

Assessments of Flight 12A.1 continued until the final analyses in November 2006. With this complex flight, SPACE analyses indicated that nine operational constraints were required to ensure all flight rules were obeyed and EPS contstraints were observed. The accuracy of SPACE results enabled analysts to predict that the SOC would go to zero with the original plan (green line), which is unacceptable for ISS operations. SPACE analysts iteratively examined different strategies, looking at all of the relevant effects (shadowing, pointing, etc.), until a strategy was identified that ensured energy balance. This solution gave flight operators confidence of a successful mission. Space Shuttle Discovery launched to ISS on December 9, 2006 and assembly Flight 12A.1 was successfully completed with 
no power system issues, in part due to the sigificant GRC and NASA Johnson Space Center (JSC) analysis activity that occurred over several years preceeding the flight.

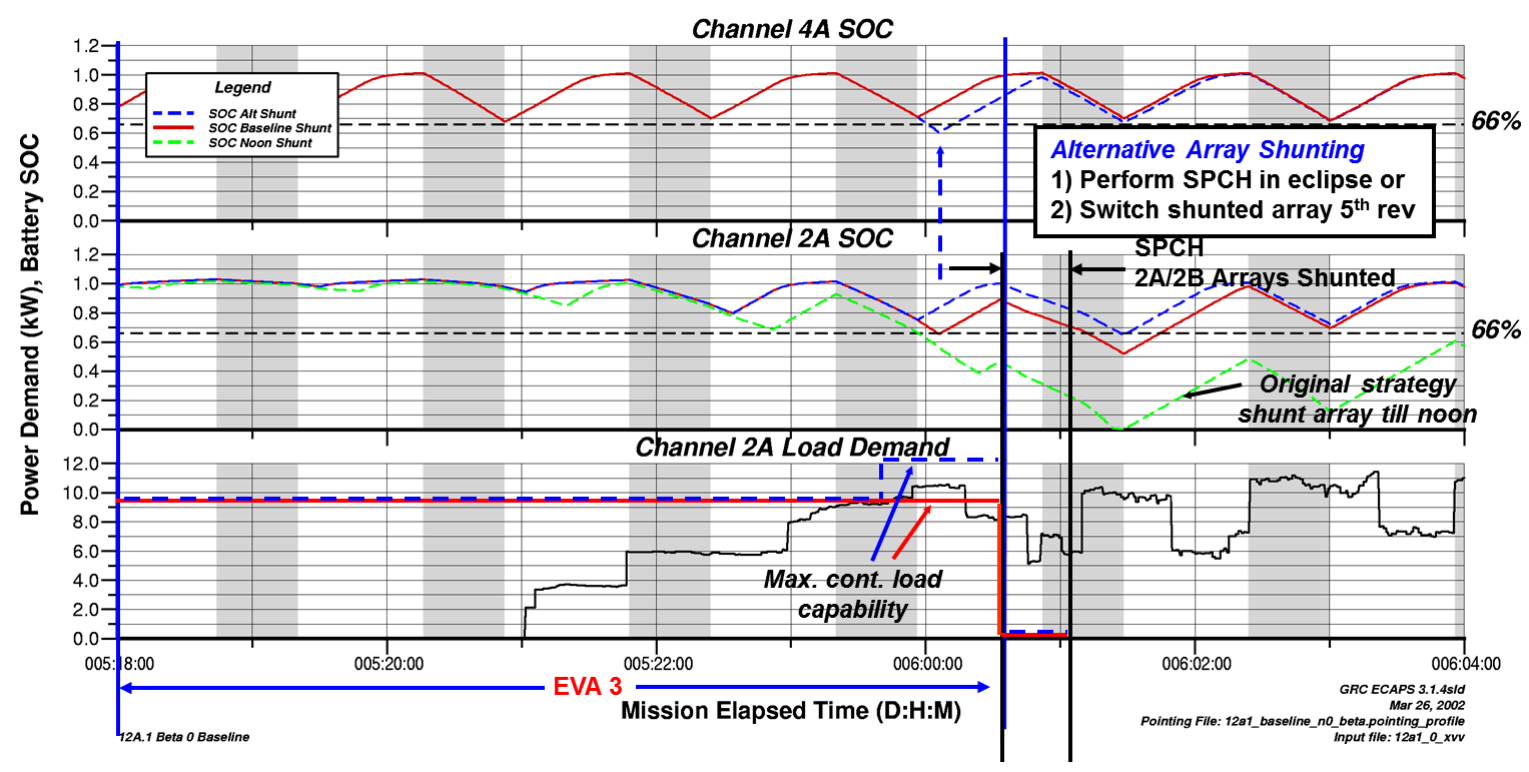

Figure 5. EVA \#3 2A/2B MBSU Reconfiguration, solar beta $0.0^{\circ}$, channel $2 \mathrm{~A}$ load demand, and battery SOC.

\section{Recent Model Updates and Results}

\section{A. Lithium-Ion Battery Model}

The $\mathrm{NiH} 2$ batteries of the ISS EPS are being replaced by Li-ion (Lithium-Ion) batteries. The first replacement batteries were installed in early 2017. Subsequent replacements are scheduled for 2018, 2019, and 2020 ${ }^{9}$. The Li-ion batteries will have a higher $\mathrm{kWh}$ capacity, higher maximum charge current, and higher charge efficiencies than the $\mathrm{NiH} 2$ batteries $^{10}$. The useable capacity of the Li-ion batteries can vary if the EOCV (End of Charge Voltage) set point is changed. The default EOCV for the Li-ion batteries is $3.95 \mathrm{~V}$, but the EOCV can be raised up to $4.1 \mathrm{~V}^{11,12}$.

A computational model for the Li-ion batteries was developed and integrated into SPACE to predict the performance of the Li-ion batteries. The Li-ion battery model in SPACE uses battery reference curves that contain battery cell resistance and cell open-circuit voltages across a span of battery DOD (Depth of Discharge) points. One reference curve set is used for battery charge and one reference curve set is used for battery discharge. The data for the reference curves came from cell characterization testing conducted by the Naval Surface Warfare Center, Crane Division. The test included multiple charges and discharges of the Li-ion cells at constant currents. The cell opencircuit voltages and cell resistances were calculated using linear extrapolation from the test data. The reference curves for the SPACE Li-ion battery model are shown in Fig. 6.

The logic to calculate the maximum allowed charge current is different for $\mathrm{Li}$-ion and $\mathrm{NiH} 2$ batteries. For $\mathrm{NiH} 2$ batteries, the ISS on-orbit software sets the maximum allowed charge current based on the battery state of charge. For Li-ion batteries, the ISS on-orbit software sets the maximum allowed charge current based on the cell voltage. If the cell voltage exceeds a certain limit, the charge current is reduced to the next set level. The next level has a new cell voltage limit. The process continues until a valid charge current is found or the last charge set level is reached ${ }^{9}$. New code was added to the SPACE Li-ion battery model routines to handle the Li-ion battery charge logic. The SPACE Li-ion battery model assumes all cells in a Li-ion battery are always at an identical charge level.

The Li-ion battery model in SPACE was completed before the installation of the Li-ion batteries. To validate the accuracy of the SPACE Li-ion battery model before the on-orbit installation of the Li-ion batteries, the model was compared to orbital rate cycle ground testing of qualification batteries. The preliminary validation showed that the model matched the ground test data for battery level voltage and current. 


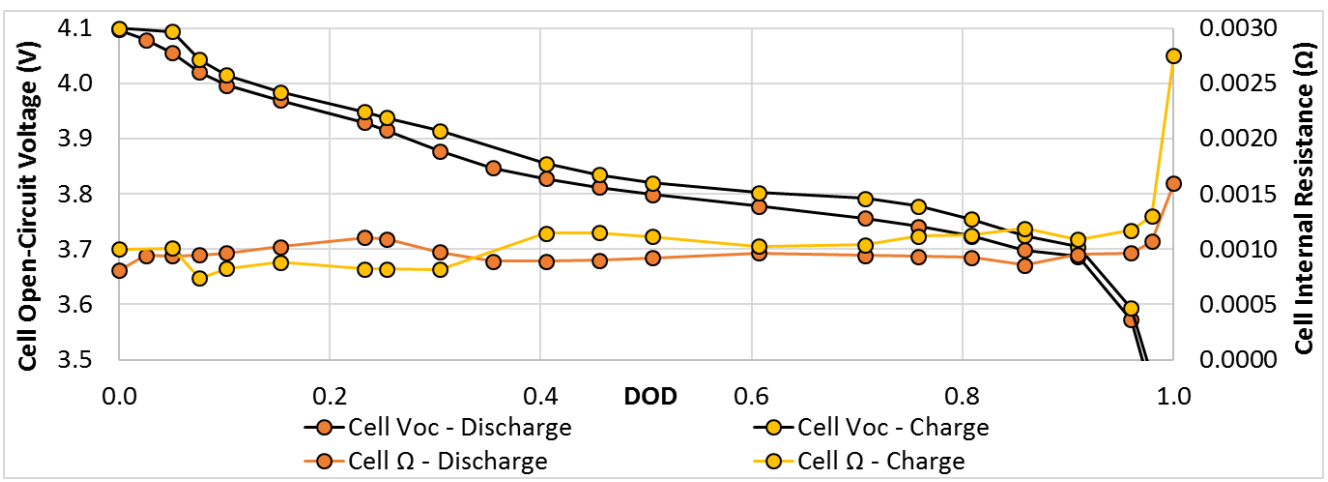

Figure 6. Reference curves for the SPACE Li-ion battery model showing cell open-circuit voltage and cell resistance for both charge and discharge for an EOCV of 4.1V. DOD values are re-scaled for different EOCV values.

Full validation of the SPACE Li-ion battery model was completed after the installation of the Li-ion batteries by comparing the model predictions to the on-orbit telemetry data from the ISS. The primary comparison metrics were the battery voltages, the battery currents, and the orbit minimum amp-hours remaining. A graphical overlay of the SPACE predictions (blue) compared to the ISS telemetry data (green) is shown in Fig. 7. Results shown for battery current include the sum of all three batteries on channel 3A. Results shown for battery voltage are the average battery voltage of all 3 batteries on channel $3 \mathrm{~A}$. SPACE calculates battery amp-hours remaining only once per orbit at the end of eclipse.

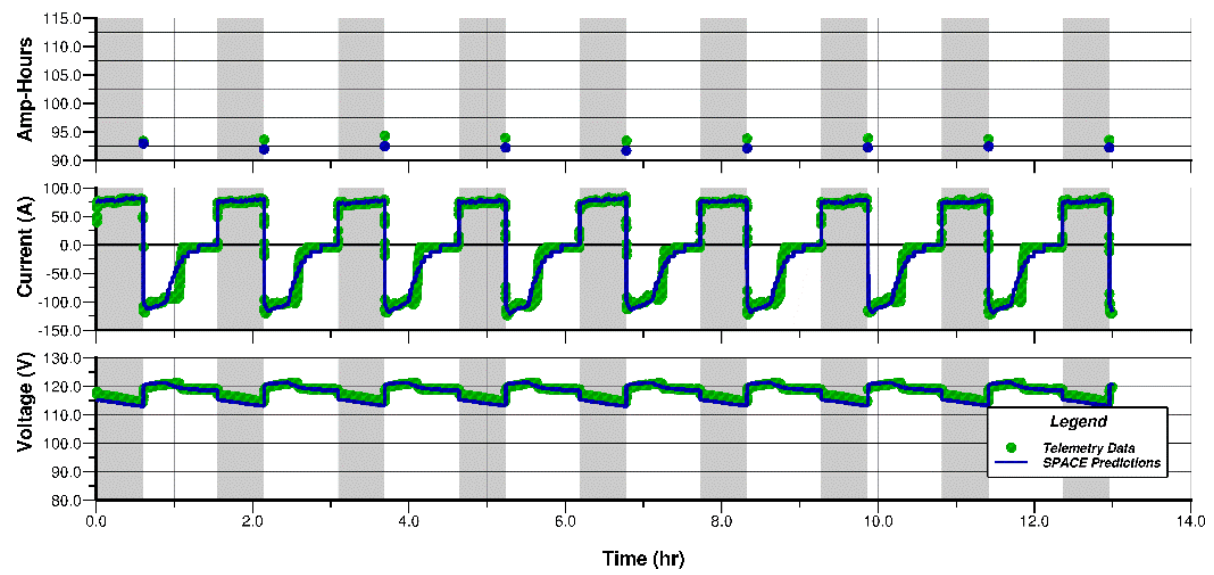

Figure 7. A graphical comparison of the SPACE Li-ion battery model predictions to the actual ISS on-orbit telemetry.

The SPACE Li-ion battery model predictions for battery voltage during discharge are lower than telemetry data. SPACE predictions are higher than telemetry data during battery charge. SPACE takes longer to step through the many charging steps of the Li-ion batteries. These inaccuracies in battery charge voltage cause the inaccuracies in battery charge current. Battery amp-hours remaining predictions are slightly lower than telemetry values. Validation efforts of the SPACE Li-ion battery model show good matching of telemetry data, but there is opportunity to improve the accuracy of the model.

\section{B. Solar Array Degradation}

In pre-launch power system capability estimates, the key contributors to solar array degradation were identified as trapped proton/electron radiation displacement damage dose, micrometeoroid and orbital debris (MMOD), contamination, thermal cycling, plasma, and darkening of the cell coverglass adhesive due to UV light. Radiation damage was presumed to be the dominant mechanism for solar array degradation, and that is still assumed to be the 
case. The original SPACE fluence model and the modified fluence model are shown in Fig. 8. The dotted blue line shows the original damage equivalent normally incident (DENI) fluence assumption for computing the reduction in solar cell maximum power (Pmax): a constant fluence of $1.89 \mathrm{E} 12$ electrons $/ \mathrm{cm}^{2}$-yr. for every year a solar array is exposed to the space environment. This value was computed assuming a constant $500 \mathrm{~km}$ altitude in solar maximum conditions. The corresponding reduction in Pmax is shown in the dotted red line. The dashed blue line was computed using actual ISS altitudes, with solar activity conditions determined from the solar radio flux at $10.7 \mathrm{~cm}$ (F10.7 index) as reported on OMNIWeb by NASA Goddard Spaceflight Center*. Using the AP8,AE8 model, the corresponding Pmax reduction is shown in the dashed red line. Recognizing that the AP8,AE8 model generally predicts low estimates of

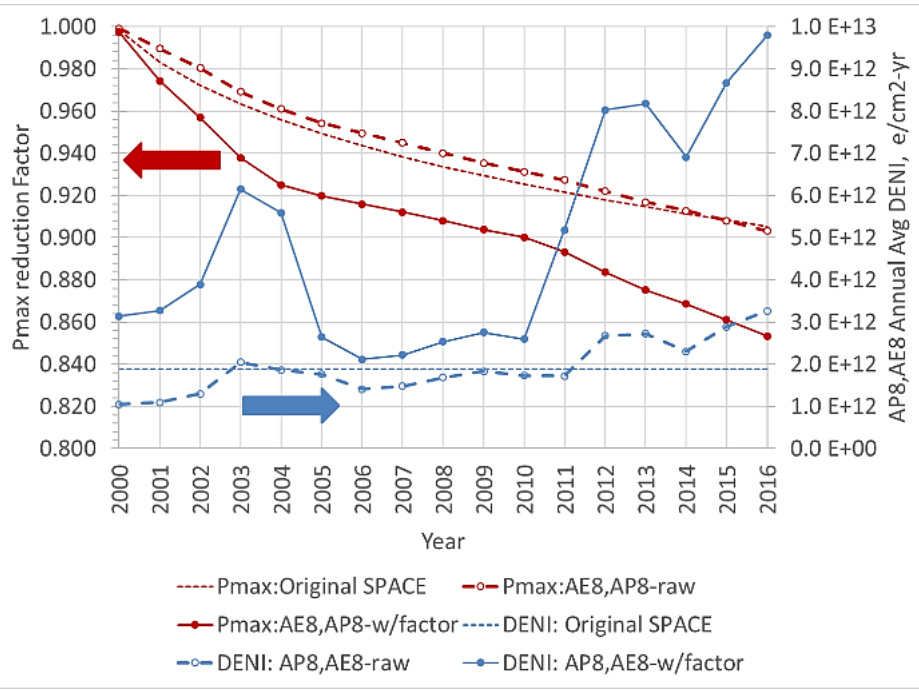

Figure 8. Solar array degradation from ionizing radiation. particle fluences for the ISS orbit ${ }^{\dagger}$, the AP8,AE8 data was scaled up by a factor of 3 (for relatively high ISS altitudes) and 1.5 (for lower ISS altitudes), shown with a solid red line.

With radiation assumed to be the primary contributor to solar array degradation, it was assumed that the updated SPACE radiation model adequately captured the dominant degradation factor. Further tuning was done by manually adjusting the SPACE MMOD solar array degradation model for each power channel, so the SPACE total solar array power output best matched the results of periodic on-orbit solar array power tests. The resulting comparison for power channel 4B on ISS segment P6 is shown in Fig. 9. Both the the "On-Orbit Shunt Test" data and "On-Orbit MaxPow Test" data were collected at orbit noon. Leveraging the fact that the ISS solar arrays are sun-facing during on-orbit shunt current tests and maximum power tests, the "OnOrbit Shunt Test" solar array power data was collected during ISS orbits that coincided with an on-orbit shunt current test and the "On-Orbit MaxPow Test" data was collected during orbits

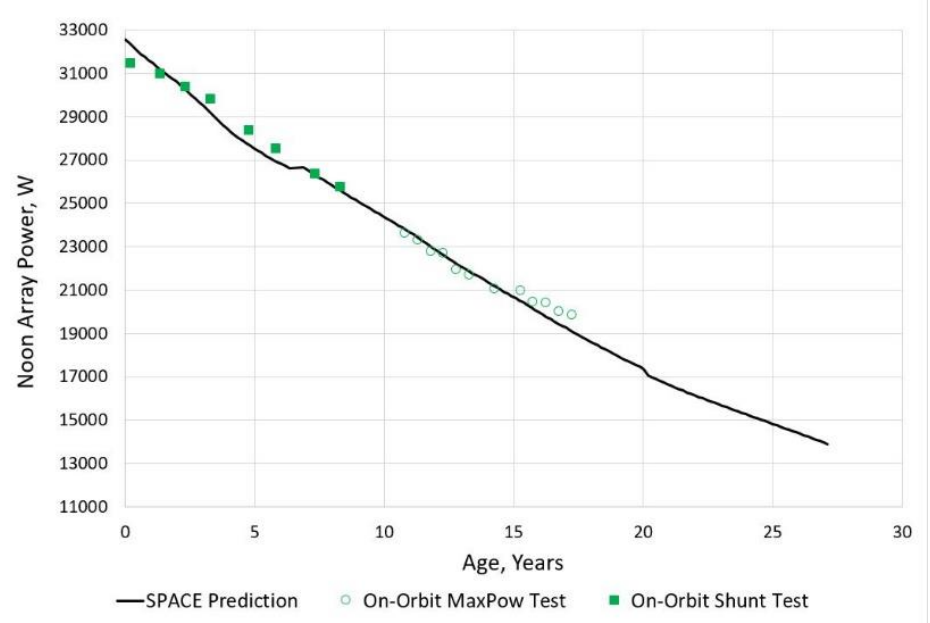

Figure 9. Power channel 4B predicted solar array power compared with on-orbit tests.

when the ISS was undergoing maximum power tests. The horizontal, flat region in the SPACE prediction after year six is due to the retraction of the 4B solar array wing required to relocate the P6 power module from its temporary location on truss segment Z1 to the permanent location outboard of segment P5. No solar array string failures have been detected on power channel 4B to date, but a predicted string failure is indicated by the vertical, flat region at year 20. Sensor uncertainty for the on-orbit data was calculated to be $1 \%$ for power channel 4B based on a GRC assessment of SSU current sensor errors from SSU acceptance test data. Because the vertical height of the error bars was roughly the same height as the on-orbit data points in Fig. 9, the error bars were removed from the figure for improved readability. Figure 9 shows that the revised SPACE degradation model closely matches on-orbit measured solar array performance data.

\footnotetext{
* https://omniweb.gsfc.nasa.gov/hw.html

${ }^{\dagger}$ T. Kerslake, Personal communication, 11/15/2016
} 


\section{Solar Array Enhancements}

NASA is investigating options to increase the power generation capability of the ISS, so that it continues to meet its electrical load demands. One possible method of increasing the power generation capability of the ISS is to add new solar arrays in front of the original solar arrays. The exact size and shape of the new arrays can vary, with possible options shown in Fig. 10, highlighted in red.

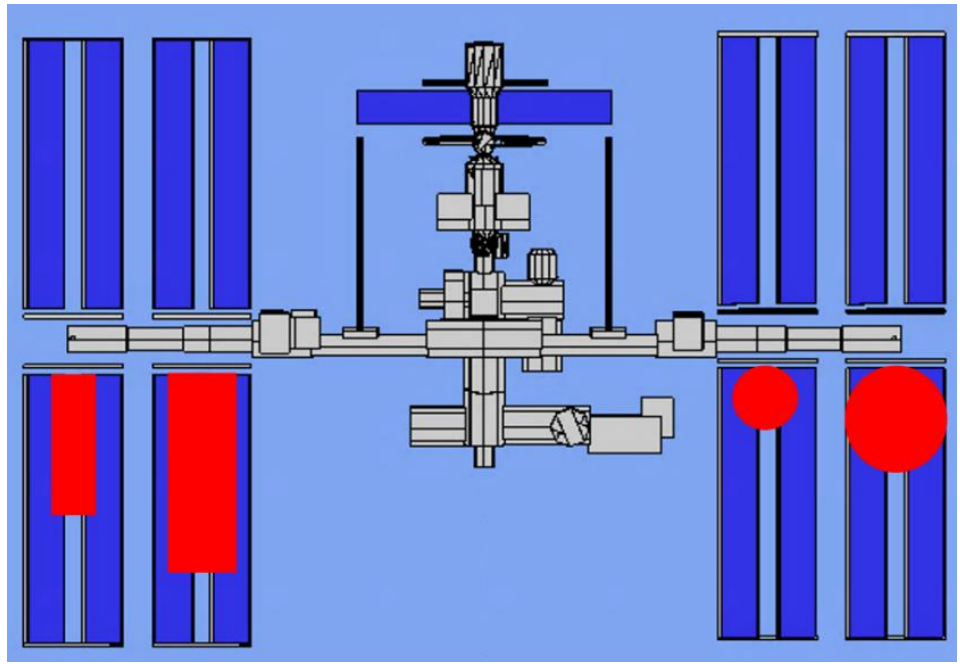

Figure 10. Model of ISS with possible solar array augmentation.

SPACE can be used to predict the power generation capability of the ISS with this new augmentation. As a proof of concept study, SPACE was used to model four new, rectangular solar arrays mounted directly in front of the original ISS solar arrays. In this study, the new solar arrays provide additional power generation to channels $1 \mathrm{~A}, 2 \mathrm{~A}, 2 \mathrm{~B}$, and 4A. These new solar arrays were modeled assuming state-of-the-art triple junction solar cells, and sized such that the performance of the ISS augmented power channels was increased to near beginning of life performance.

A single-orbit analysis was performed to determine the power generation with the solar array augmentation. This single-orbit analysis modeled the ISS in low-earth orbit with a solar beta angle of 0 degrees. The solar array power generation of the augmented channels is shown in Fig. 11. The shaded portion shows the eclipse duration of the orbit. The remaining portion of the orbit is spent in sunlight. Since the new solar arrays are located directly in front of the

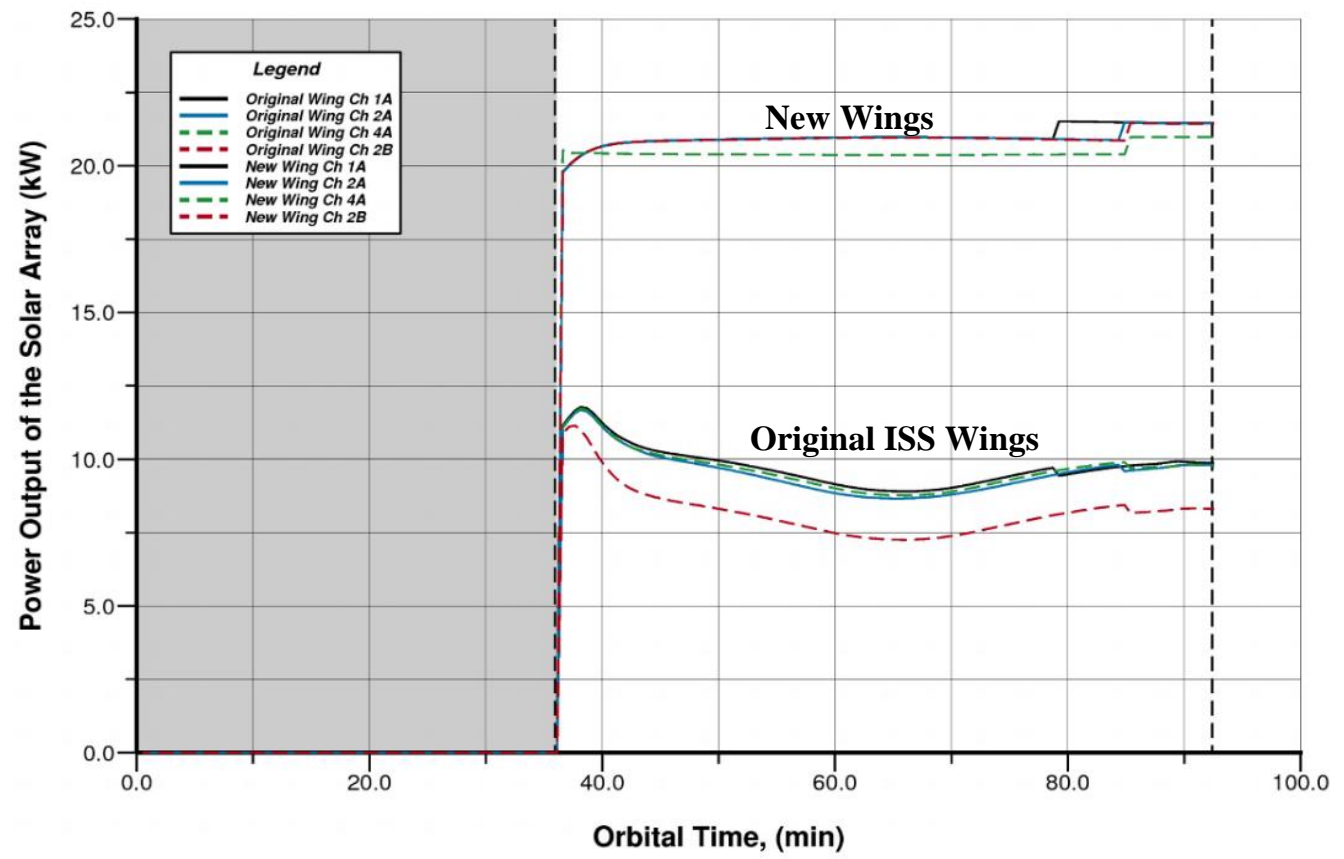

Figure 11. Output power of the solar array wings. 
original ISS solar arrays, the shadowing caused by the augmentation must be taken into account when predicting the new power performance. The new solar arrays used to augment the ISS power channels generate an average of more than $20 \mathrm{~kW}$ during the insolation period, while the original ISS solar arrays generate an average of $10 \mathrm{~kW}$ during the insolation period.

With this augmentation, the total power generated by the solar arrays on the augmented channels is increased as shown in Fig. 12. Without the solar array augmentation, each power channel generates an average of 20-25 kW during the insolation period. With the new augmentation, the ISS solar arrays generate an average of $30 \mathrm{~kW}$ during the insolation period, resulting in a total net gain of $25 \mathrm{~kW}$ for the ISS during insolation. Towards the end of the insolation period, the power levels begin to drop for the augmented solar arrays in what looks like a "staircase". This is due to the SSU shunting solar array strings, because the solar array power exceeds the load demand of the ISS. This is less pronounced without the augmentation, as the power level is significantly lower.

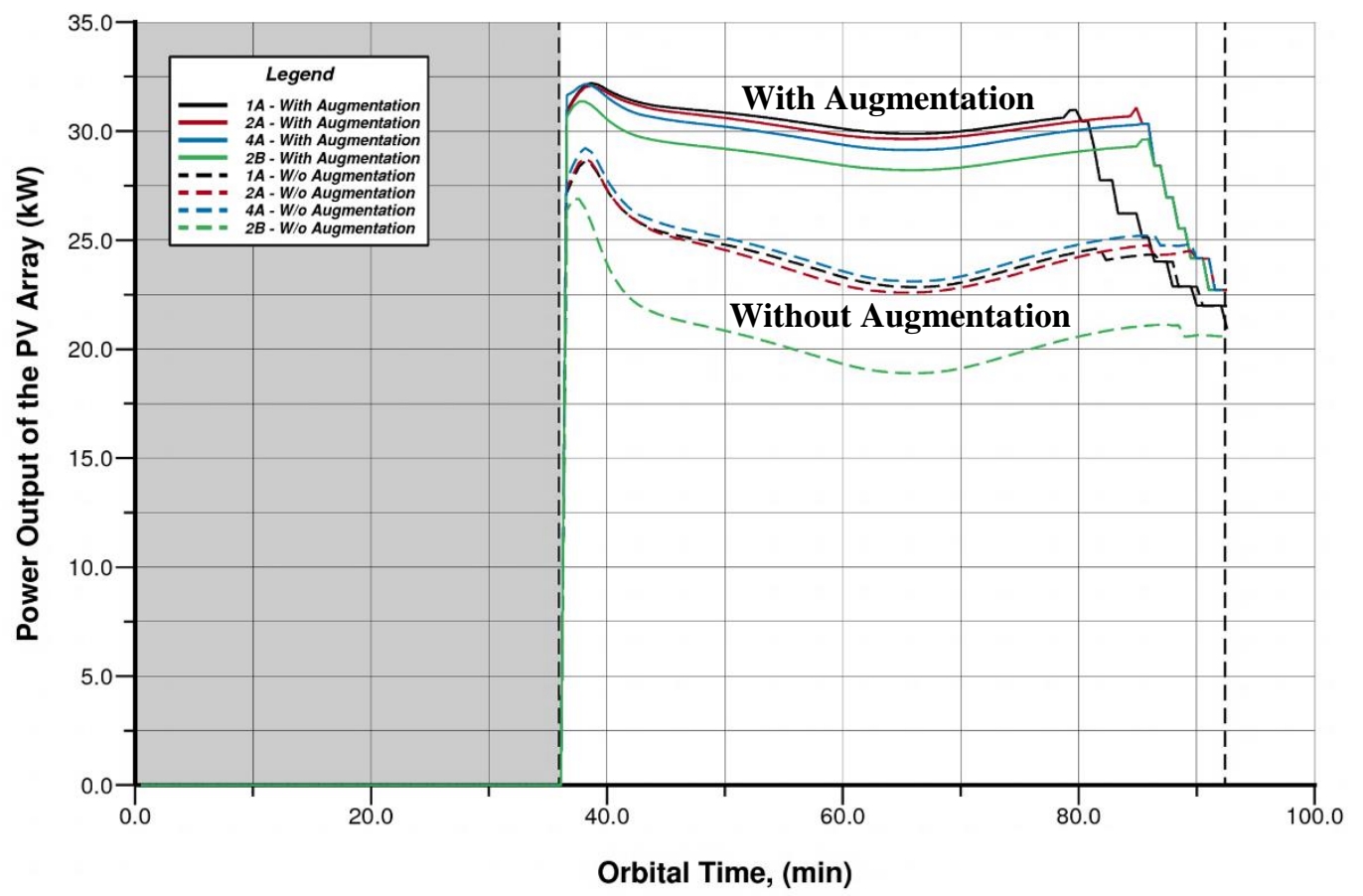

Figure 12. Output power of the PV array with and without augmented solar arrays.

As expected, the solar array enhancements increase the total power generation for channels $1 \mathrm{~A}, 2 \mathrm{~A}, 2 \mathrm{~B}$, and $4 \mathrm{~A}$. This proof of concept study demonstrates the ability of SPACE to model new solar arrays, which can be used to augment the current ISS electrical power system. Once NASA decides on the exact size, shape, and configuration of the new solar arrays, as well as the number of channels to augment, SPACE can be used to analyze the performance of the augmented ISS electrical power system.

\section{Impact of Changing Environment}

ISS maximum power tests were conducted in fall 2016 at $145 \mathrm{~V}, 150 \mathrm{~V}, 155 \mathrm{~V}$, and $160 \mathrm{~V}$ to determine which SSU voltage set point resulted in the maximum power generation. To address the observed variations in solar array power per string during these solar array maximum voltage tests, changes in Earth's albedo were considered as a possible explanation. When the ISS solar arrays are sun-facing, sunlight reflects off the Earth's surface and encounters the front side and/or backside of the solar arrays. Mounted on a solar transparent substrate, ISS solar cells are capable of backside power generation ${ }^{18}$. A possible explanation for the variations in power generation is that non-negligible amounts of sunlight were being reflected off Earth's surface onto the backside of ISS solar cells, causing increases in power generation related to the albedo of the Earth along the Space Station's ground track. This possible explanation was tested by overlaying the ISS ground tracks onto satellite imagery of the Earth at the time telemetry data was recorded for the voltage tests, estimating the albedo from the satellite images, and comparing this information with the measured solar array power per string. In an early application of this method, on-orbit photographs taken from the 
ISS were used to adjust the albedo value in SPACE for a comparison with on-orbit measured solar array operating current ${ }^{\ddagger}, 13$.

Earth's albedo is the fraction of solar visual, or short-wave, radiation that is reflected off the Earth's surface back into space ${ }^{15}$. Larger values of albedo indicate greater reflectivity. Primarily a function of surface terrain, latitude, and climate, Earth's albedo ranges from as low as 0.06 over the ocean to 0.90 over regions covered with fresh snow ${ }^{14}$. In addition, Earth's albedo undergoes gradual, seasonal fluctuations in addition to more rapid variations as a result of changing cloud cover ${ }^{15}$.

Albedo variation with cloud type adds a layer of complexity to estimating the albedo at a specific location on Earth's surface. Cloud albedo largely depends on the water mass contained in the clouds, the size and shape of the water droplets, and the distribution of these droplets in space $^{15}$. A practical approach to estimating the albedo of clouds in satellite imagery for the purposes of this work was to identify the cloud type and use the average albedo value for that type. Clouds were grouped into four categories, by increasing albedo: cirrus, cumulus, stratus, and cumulonimbus. No attempt was made to calculate a numerical value for cloud albedo. This method of identifying and ranking cloud types in terms of reflectivity was used to qualitatively assess trends in increasing/decreasing albedo. Figure 13 shows the cloud types identified in Geostationary Operational Environmental Satellite (GOES) images.

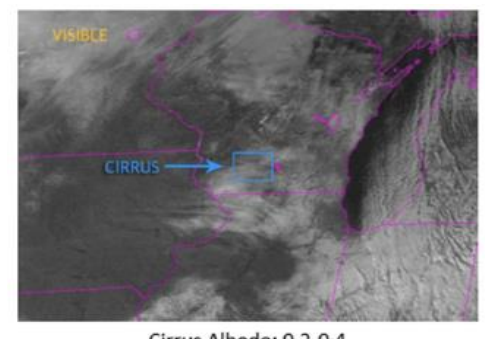

Cirrus Albedo: 0.2-0.4

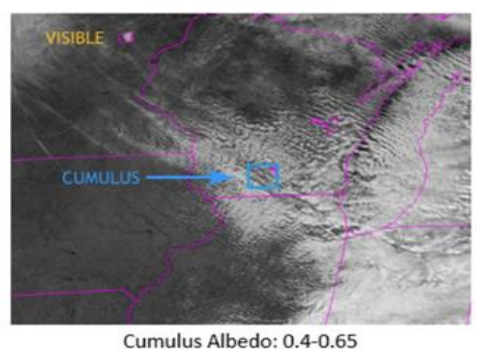

Cumulus Albedo: 0.4-0.65

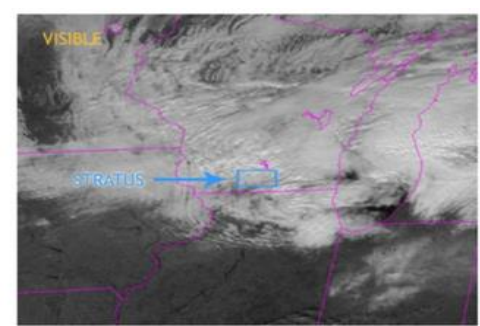

Stratus Albedo: 0.75

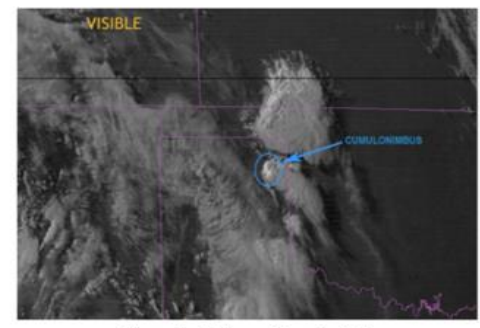

Cumulonimbus Albedo: 0.9

\section{Figure 13. Cloud types identified on GOES satellite images with albedo} ranges ${ }^{8}$.

A range of albedo values categorized by surface type is given in Table 2. For prior SPACE analyses, an average albedo value of 0.27 has been used. While an average albedo value is appropriate in many situations, the wide range of albedo values that the ISS might encounter along its orbit suggests that an average albedo of 0.27 is not always indicative of the amount of sunlight reflected onto the front and/or back of ISS solar arrays. For example, the ISS could see a sudden change in albedo during a transition from ocean to a sand desert. On a solar array power generation curve, we would expect this sudden increase in albedo to correspond to an increase in power generated. The amount of sunlight reflected onto the ISS also impacts solar array temperatures. Higher solar array temperatures are expected for higher values of Earth's albedo and vice versa. A detailed thermal analysis was not included as part of this analysis.

Table 2 Albedos of different surface types ${ }^{6,16}$

\begin{tabular}{|l|l|}
\hline \multicolumn{1}{|c|}{ Surface Type } & \multicolumn{1}{|c|}{ Albedo } \\
\hline Fresh snow & $0.80-0.90$ \\
\hline Sand & $0.30-0.35$ \\
\hline Grass, cereal crops & $0.18-0.25$ \\
\hline Deciduous forest & $0.15-0.18$ \\
\hline Coniferous forest & $0.09-0.15$ \\
\hline Tropical rainforest & $0.07-0.15$ \\
\hline Water bodies & $0.06-0.10$ \\
\hline Cirrus Clouds & $0.2-0.4$ \\
\hline Cumulus Clouds & $0.4-0.65$ \\
\hline Stratus Clouds & 0.75 \\
\hline Cumulonimbus Clouds & 0.9 \\
\hline
\end{tabular}

¥ ISS EPS Performance Analysis, Peer Review: SPACE Validation Against On-Orbit Telemetry, 23 August 2001. 
Telemetry data from the fall 2016 solar array maximum voltage tests shows solar array power variations of 0-700 $\mathrm{W}$ over each orbit of the maximum voltage tests. Significant variations were also observed in the shunt current telemetry data, as shown in Fig. 14. Shunt current is generated in times of excess power generation (see Section II) and is expected to increase with albedo and solar cell temperature. Both albedo and solar cell temperature increase with greater amounts of reflected sunlight onto the solar arrays. Therefore, shunt current is a useful parameter with which to compare voltage setpoints for maximum power generation. These variations in power generation, observed previously $y^{4,17,18}$, prompted further investigation into the effect of changing albedo conditions on power generation.

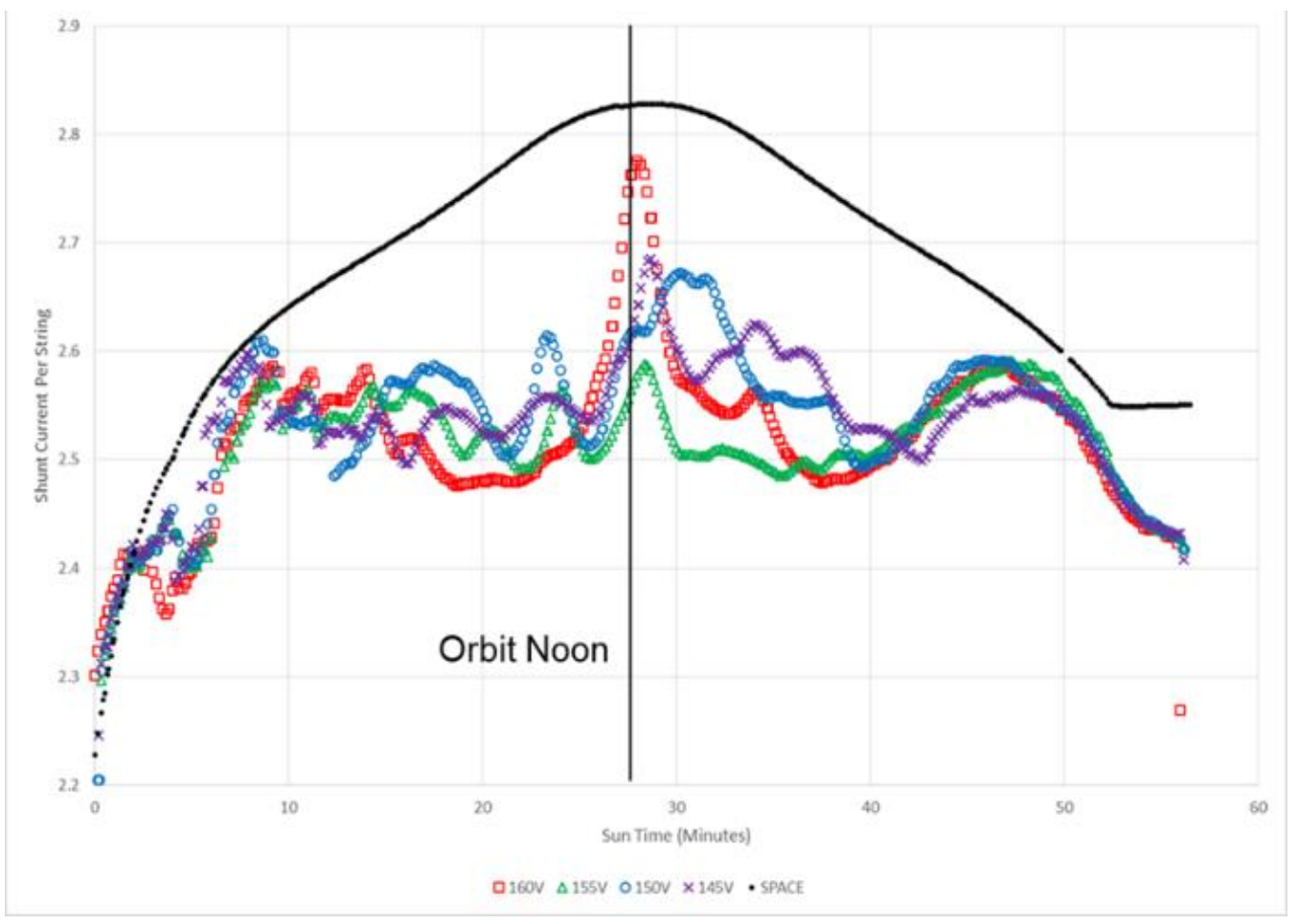

Figure 14. ISS telemetry shunt current per string data during high power tests.

Systems Tool Kit ${ }^{\circledR}$ was used to plot the ISS ground track for the maximum power tests. The analysis focused on a ten-minute window centered at orbit noon where the variations in the power generated at the four voltage set points was significant. For the purposes of this analysis, orbit noon is defined as 28 minutes after dawn for each sun period. The ground tracks were plotted on available GOES-13 and GOES-14 satellite images with time stamps that most closely matched the data collection periods. Figure 15 shows the ISS position marked in red at orbit noon and its ground track in teal for all four orbits of the maximum power test. 
Figure 15 shows that the ISS was flying over Western Africa (sand desert, combined with ocean) during the $160 \mathrm{~V}$ test, Venezuela (equatorial forest, combined with ocean) during the $150 \mathrm{~V}$ test, an oceanic region west of Central America during the $145 \mathrm{~V}$ test, and an oceanic region north of Brazil during the $155 \mathrm{~V}$ test. Without considering cloud cover or other environmental effects, we would expect the $160 \mathrm{~V}$ case to experience the highest albedo, followed by the $150 \mathrm{~V}$ case, and the last two cases $(145 \mathrm{~V}$ and $155 \mathrm{~V})$ to have the lowest.
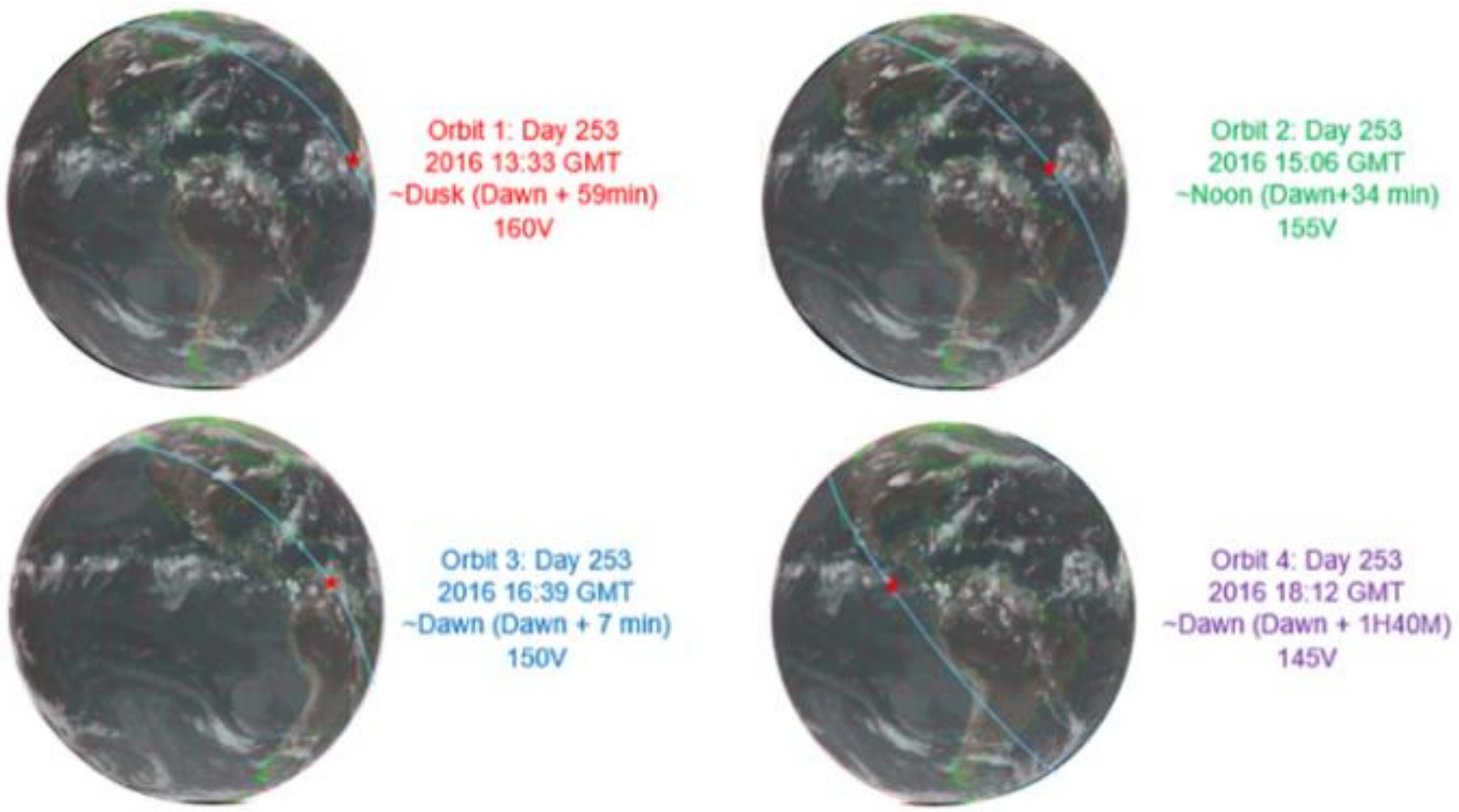

Figure 15. ISS ground tracks plotted over satellite imagery of Earth during high power tests.

In terms of increasing cloud cover, the tests can be qualitatively ranked as follows from least to greatest albedo: $155 \mathrm{~V}, 150 \mathrm{~V}, 145 \mathrm{~V}$, and $160 \mathrm{~V}$. Considering Fig. 14 once again, recall that increased amounts of reflected sunlight onto the solar arrays (increased albedo) will result in increased shunt current. Hence, we expect the voltage tests with higher shunt current values to match the voltage tests with higher estimated albedo. This is clearly observed for the $160 \mathrm{~V}$ case, which corresponds to both the highest shunt current and the highest albedo at orbit noon. Similarly, the $155 \mathrm{~V}$ case corresponds to both the lowest shunt current and the lowest estimated albedo at orbit noon. The $145 \mathrm{~V}$ and $150 \mathrm{~V}$ have comparable surface albedo estimates, but greater cloud cover is observed for the $145 \mathrm{~V}$ case. Once again, this is consistent with the shunt current data at orbit noon. Higher shunt currents are indicative that the solar array can generate more current, and thus power, overall. The result of this analysis suggests that the amount of backside solar array power generation the ISS produces is directly proportional to the estimated albedo along its ground track. Therefore, care should be taken in drawing conclusions from on-orbit data around orbit noon when comparing results from maximum voltage tests.

\section{E. Certification for Flight Readiness (CoFR)}

Since ISS assembly completion (see Section III), ISS EPS analyses have morphed from Verification Analysis Cycles (VACs) to Certification of Flight Readiness (CoFR) analyses. Whereas VACs concentrated on the ISS assembly and EPS assembly missions with the space shuttle as the visiting vehicle, CoFRs concentrate on analysis of visiting vehicle missions from the European Space Agency, SpaceX, Orbital-ATK, and the Japanese Space Agency.

The CoFR analyses, similar to the preceding VAC analyses, are detailed mission timeline EPS analyses. CoFR inputs include the planned time-phased electrical loads, ISS orbit mechanics and attitudes, planned solar array operations, EPS hardware and software limits, flight rules, restrictions on the minimum acceptable battery SOC (for $\mathrm{NiH}_{2}$ batteries) or battery amp-hour remaining (for Li-ion batteries), and EPS configuration. The result of a CoFR analysis determines if the ISS EPS can support the planned mission. Analyses include events when some or all of the ISS solar arrays are parked, such as during approach and capture of a visiting vehicle, exterior robotic payload installation or ISS maintenance, and EPS modification/enhancements such as battery replacement. In the event 
solutions cannot be identified by moving loads between connected power channels, electrical power downs, differing solar array pointing strategies, or operations modifications, then solar beta-cutouts are recommended, which restrict launches or activity to favorable dates when the analysis shows the requirements can be met.

The GRC CoFR analyses are performed for the Vehicle Integrated Performance, Environments, and Resources (VIPER)/ISS Program Office (ISSPO) in support of the CoFR process. The CoFR process certifies that all the subsystems can support the planned mission within the subsystem constraints and flight rules.

An example of a recent CoFR analysis for SpaceX Dragon cargo mission 13 is shown in Figure 16. During this mission, the SpaceX Dragon vehicle berths to ISS, and a science experiment payload is robotically removed from the SpaceX Dragon vehicle and installed on an exterior payload carrier. This robotic activity required the port SARJ to be parked for seven hours to accommodate robotic clearances. Figure 16 depicts the results using two BGA biasing strategies during a science experiment installation. A BGA biasing strategy intentionally off-points the solar arrays to reduce shadowing on adjacent solar arrays, increasing overall power and/or reducing aerodynamic drag. Four parameters are shown on the plot: solar array output power, the time-phased electrical load demand, battery time-to$82 \mathrm{~V}$, and battery SOC. The battery time-to- $82 \mathrm{~V}$ parameter is computed by SPACE once per orbit. This value indicates the amount of time the ISS EPS could continue to operate at a constant current load before the system would begin to shed loads at the low battery voltage cut-off of $82 \mathrm{~V}$. In prior discussions with JSC mission operations personnel, a goal of a minimum of 40 minutes-to- $82 \mathrm{~V}$ for all operating scenarios was recommended. The blue box highlights the time when the port SARJ is parked for the science experiment installation; the BGAs continue sun tracking. Note that with the port SARJ parked, power channel $2 \mathrm{~A}$ is no longer in energy balance and thus the battery SOC walks down from the full SOC value of 1.0 to 0.65 or 0.55 over five orbits depending on solar array biasing strategy used. This plot shows that using one version of the BGA bias strategy (green dots) results in an acceptable time-to-82V, but a different version of the BGA bias strategy (red dots) results in lower than 40 minutes-to-82V while maintaining the battery SOC at or above the 0.55 goal.

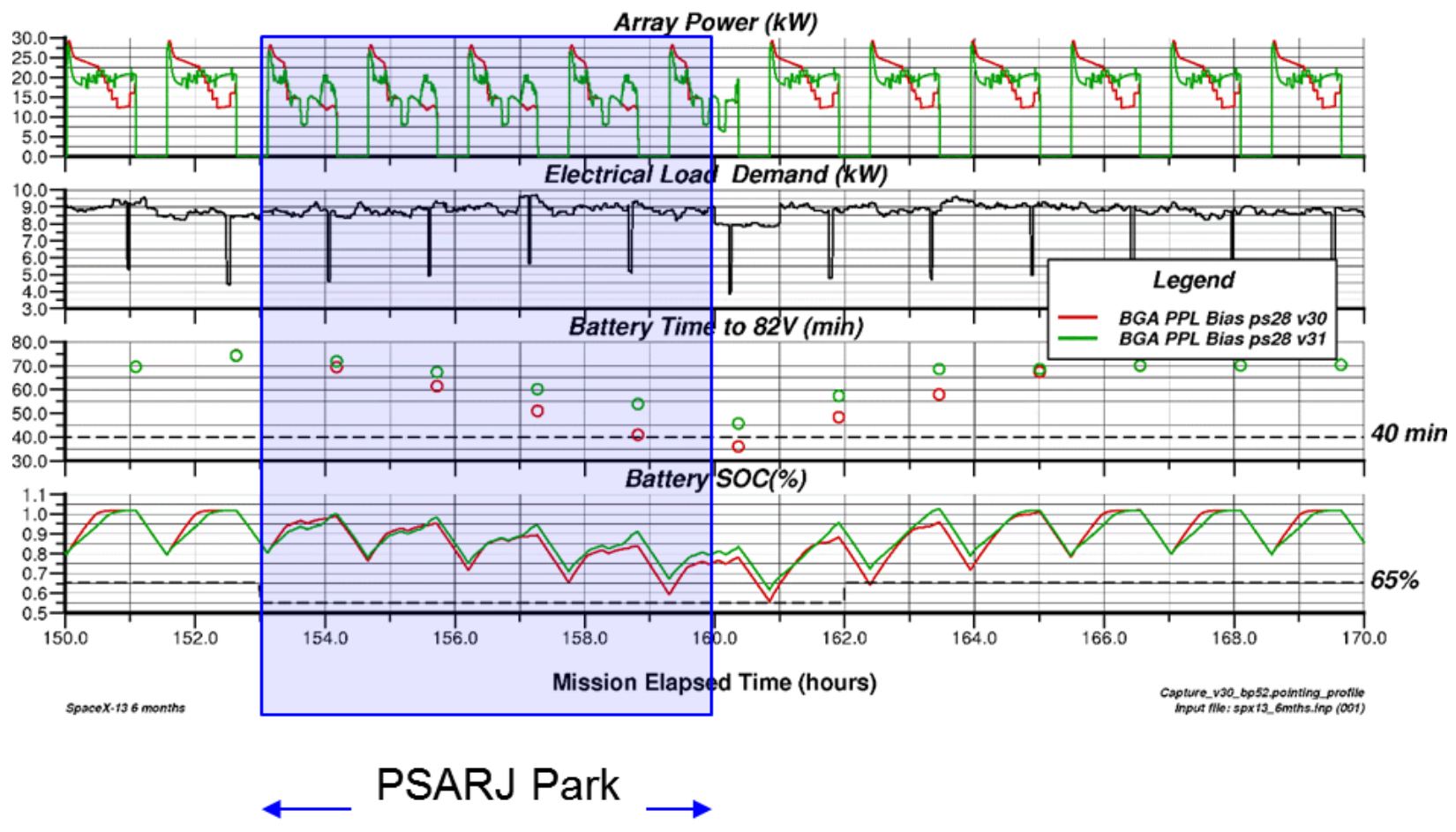

Figure 16. Channel 2A assessment during a science experiment installation in fall 2017.

\section{F. Recent Validation Episodes}

A recent validation episode, which began in December 2015, compared model predictions with on-orbit data across a range of conditions that included high negative solar beta angle operations. In a subsequent validation episode, nine flights were assessed from early 2016 through early 2017 over a wide span of solar beta angles $\left(-52^{\circ}\right.$ to $\left.+70^{\circ}\right)$ to protect against a launch delay. These cases are illustrated in Fig. 17, where the images at the bottom show the ISS 
configuration. Following the change in the solar array degradation model (see Section IV.B), all previous validation cases were re-run. In total, 30 cases were re-run in what was referred to as a trending analysis.

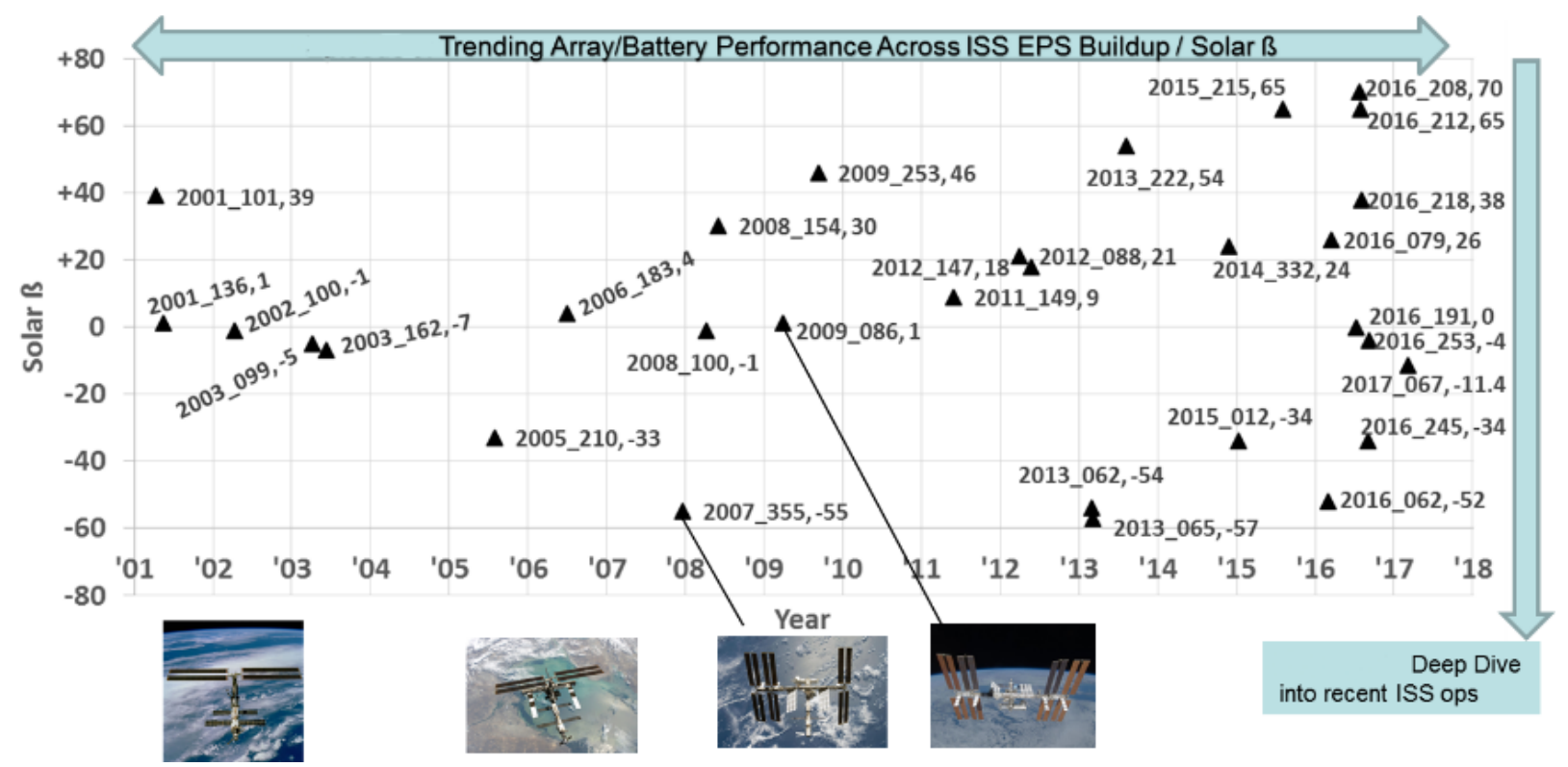

Figure 17. SPACE validation cases throughout ISS operating life.

The trend of the SSU operating current-per-string average error for power channel 4B across the 30 cases is shown in Fig. 18. The black circular points (labeled "Old") refer to a prior version of SPACE where solar array degradation was increased on power channel 4B by increasing the radiation fluence by a factor of three. The red " $X$ " points (labeled "New") show the results with the revised solar array degradation model. SPACE generally has lower absolute errors with the revised solar array degradation model.

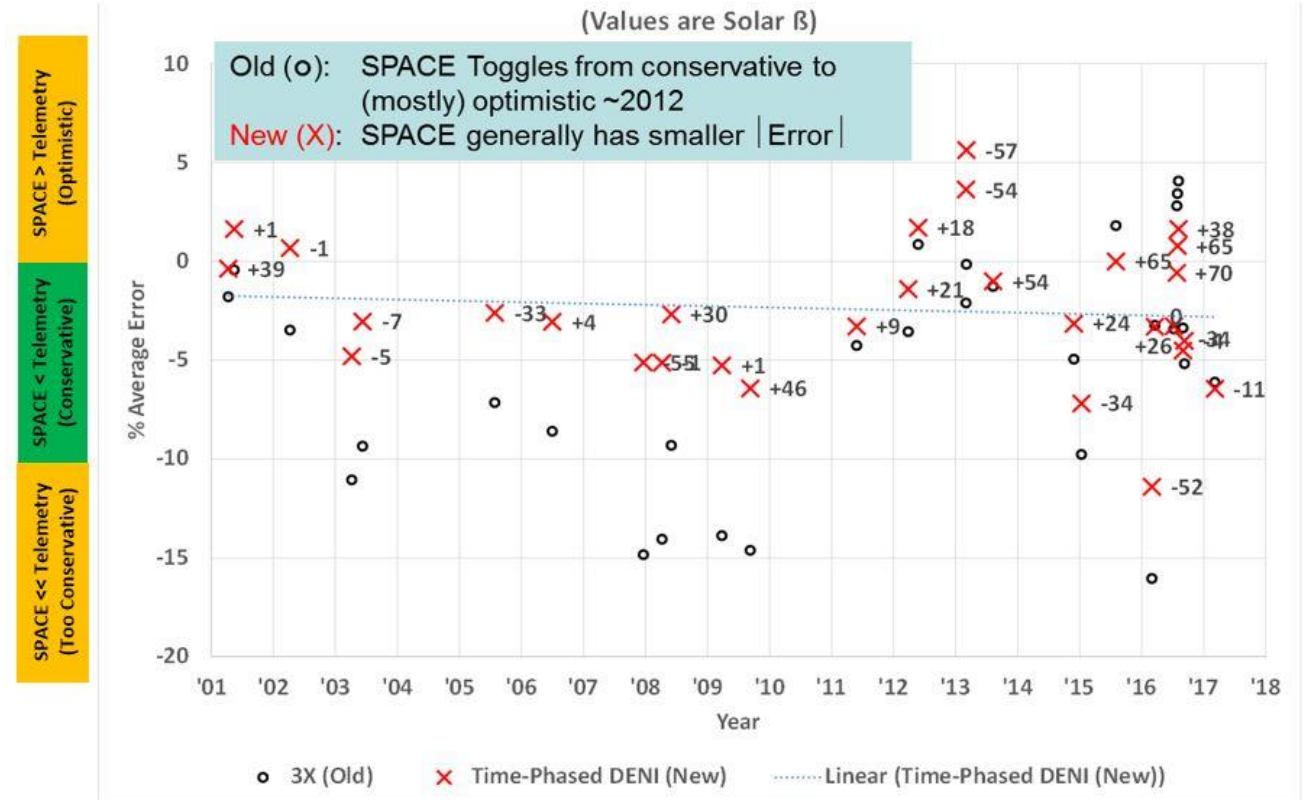

Figure 18. Channel 4B SSU current-per-string average error between SPACE and on-orbit data with two degradation models. 
A key output parameter from SPACE analyses is minimum allowed battery $\mathrm{SOC}$ for $\mathrm{NiH}_{2}$ batteries. A comparison of SPACE battery SOC predictions and on-orbit data is shown in Fig. 19. Out of 191 cases across battery ages and minimum SOC values, $173(91 \%)$ cases are in the "sweet spot" where the difference between SPACE and on-orbit values for battery minimum SOC is \pm 0.03 .

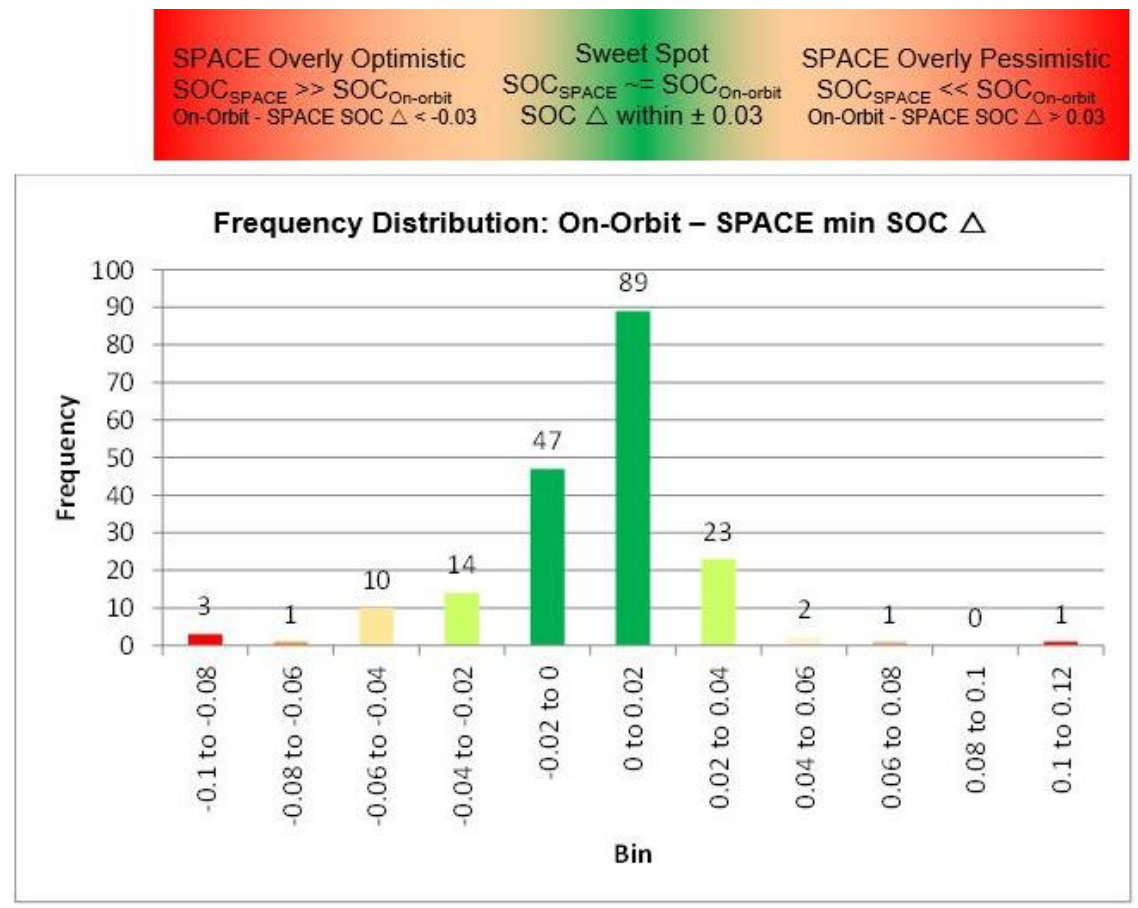

Figure 19. SPACE and on-orbit data comparison for battery SOC.

Figure 20 shows the battery current, voltage, and SOC for power channel 1B during the validation episode that assessed nine flights from early 2016 through early 2017. Power channel 1B is a representative example of a case that falls into the "sweet spot". A comparison of the on-orbit data (green line) and SPACE predictions (blue line) show that all errors are less than $7 \%$ and battery voltage errors are less than $1 \%$ for SOC values less than 0.8 .
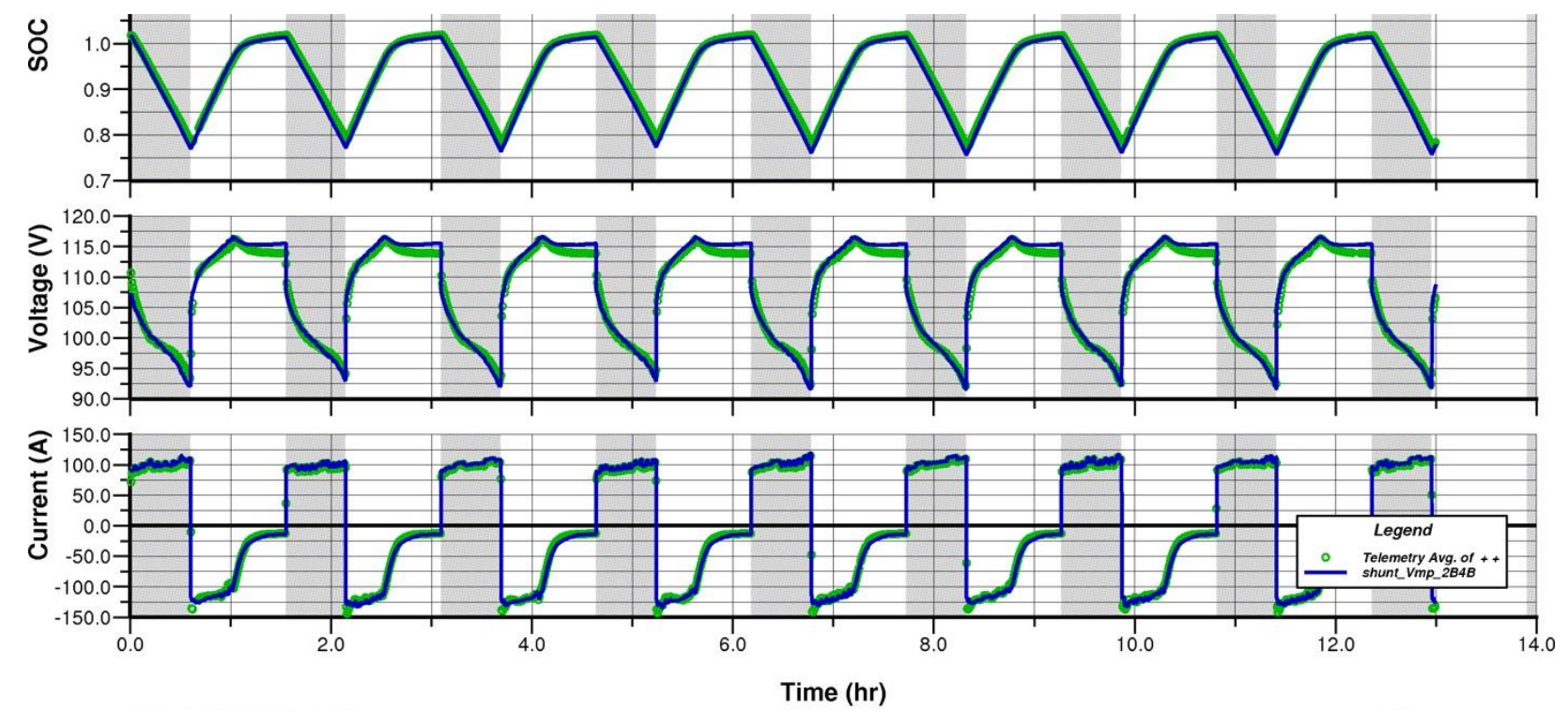

Figure 20. Battery sweet spot: power channel 1B battery current, voltage, and SOC. 
Figure 21 provides an example of a case where the SPACE prediction (blue line) is overly pessimistic when compared to on-orbit data (green line). In this case, the largest discrepancy in SOC occurs at $~ 11.5$ hours, where the difference between on-orbit and SPACE values for SOC is +0.1 . In addition, the plot of battery current over time shows that SPACE predicts a higher discharge current during the sun period compared with on-orbit data. The result is a faster SOC decrease compared with on-orbit data.
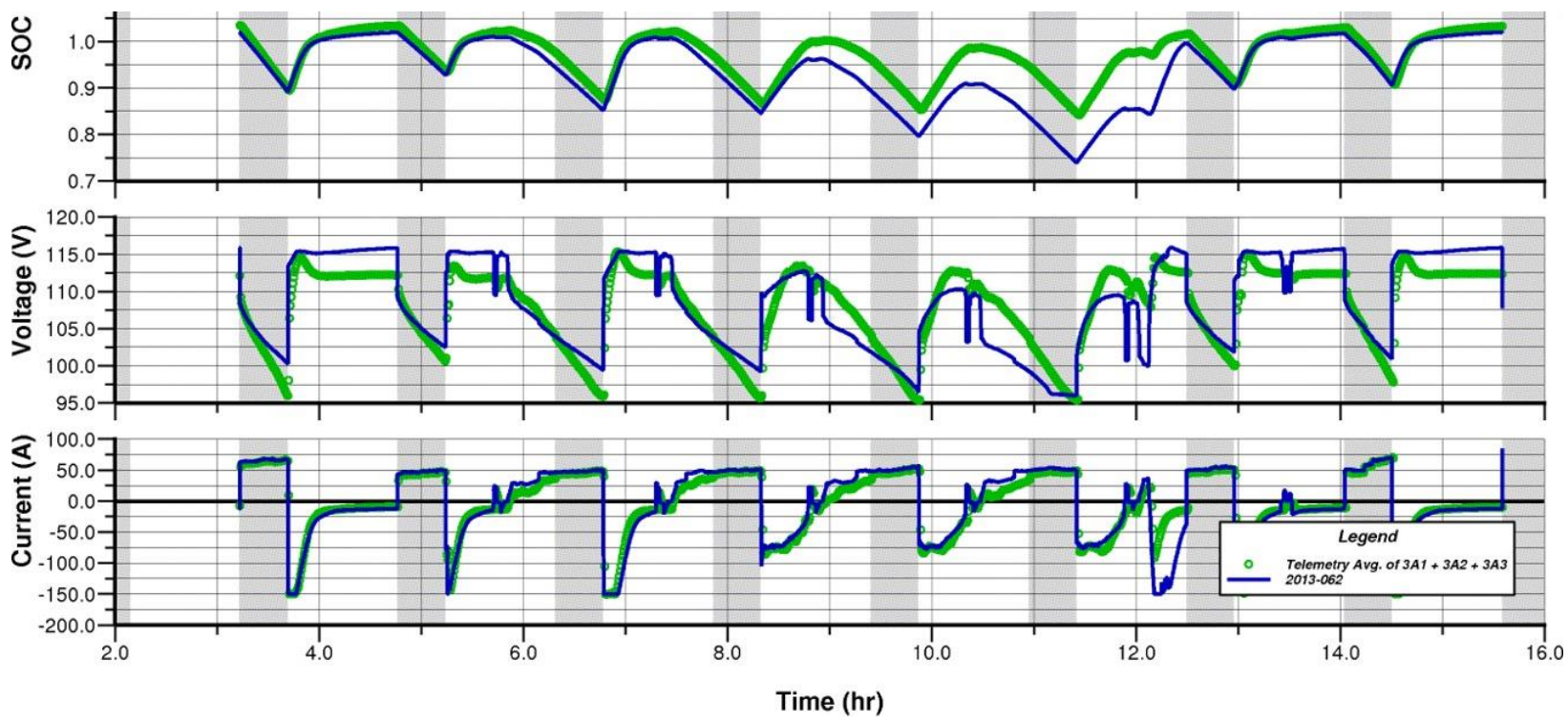

Figure 21. SPACE overly pessimistic: power channel 3A battery current, voltage, and SOC.

The results in Fig. 21 correspond to the only case that falls into the rightmost bin for overly pessimistic SPACE predictions shown in Fig. 19. This was a complex case due to a combination of high solar array off-pointing and high shadowing. The high shadowing resulted in a small SPACE solar array performance error, which propagated into an SOC error of 0.1. For orbits in energy balance, a small SPACE/on-orbit data error in array performance has little impact on battery SOC predictions. The majority of cases, such as the example shown in Fig. 20, fall into the "sweet spot" characterized by good matching between SPACE predictions and on-orbit data.

\section{G. SPACE-MPCV}

NASA is currently developing the Orion spacecraft to carry crew to deep space and safely return the astronauts to Earth. The Orion EPS consists of Li-ion batteries in the Crew Module and solar arrays mounted on the Service Module ${ }^{19,20,21}$. The Service and Crew Modules are under development by the European Space Agency (contractor: Airbus Defence and Space) and NASA (contractor: Lockheed Martin) respectively. In 2006, the SPACE-ISS code was modified to model the Orion EPS architecture. The advantage of having SPACE modeling heritage contributed to the rapid, detailed development of the SPACE-MPCV code. Many analyses with SPACE-MPCV have been performed for the Orion program office.

Examples include:

- SPACE-MPCV and the Lockheed Martin Orion power code performed model-to-model code comparisons to validate the performance of each Orion EPS code. The validation effort compared both Orion battery model and solar array model characteristics.

- Early MPCV power generation analyses conducted using SPACE-MPCV included assessments of 1-axis versus 2-axis solar array tracking and their effects on power generation. Analyses were also performed for the solar array gimbal keep-out-zones, gimbal speeds, and the impact of albedo on power generation. In addition, a dead bus recovery study assessed the loss of Orion's EPS during an eclipse and calculated the amount of power the solar arrays can generate once insolation occurs.

- Recent analyses have assessed the effect of different attitudes imposed on Orion from the launch vehicle upper stage on the incident solar flux on the solar arrays, determined the impact of auxiliary trans-Earth- 
injection burns on power generation with locked solar array gimbals, and analyzed the effect of reaction control system thruster plume impingement on Orion solar arrays ${ }^{22}$.

- SPACE-MPCV has also performed analyses for future missions, such as an analysis to quantify the continuous power available to MPCV loads during rendezvous, proximity operations, and docking while mated to a co-manifested payload and transferring to a Lunar Orbital Platform - Gateway orbit. Another example is the eclipse cutout estimate analysis, which determined the duration of an eclipse during an EM3 mission. Finally, a recent penumbra eclipse study assessed the temperature the solar arrays can reach in penumbral eclipse, the amount of solar flux required to warm the solar arrays, and the time required to reach minimum solar array temperature during penumbral eclipse.

SPACE-MPCV has been used to perform analyses that have determined power generation under a wide range of on-orbit conditions, environments, and constraints. Furthermore, SPACE-MPCV has been used to perform analyses that validated model predictions prior to test data becoming available and even contributed to the development of the Orion power system design.

\section{H. SPACE Next Gen}

New capabilities are added into SPACE as part of a continual improvement effort titled "SPACE Next Gen." In addition to the Li-ion battery and solar array augmentation models discussed in Sections IV.A and IV.C respectively, new capabilities include the ability to model non-circular orbits and the ability to change BGA biasing strategies midanalysis. SPACE Next Gen seeks to incorporate modern coding features, provide structure to the family of existing SPACE codes, and allow for rapid development of code to assess the capabilities of EPS architectures for future NASA space power systems. This effort is being led by early-career employees on the team, with experienced developers providing guidance and support.

Future work for the SPACE Next Gen team includes an effort to modularize and generalize SPACE. Breaking the code into logical modules, a generalized version of SPACE would make it easier for users to modify and reduce source code that has a complex control structure. While the current SPACE code is procedural in nature, there is also a desire to shift towards object-oriented programming to improve organization of the code. By arranging SPACE functions into a hierarchy of classes and subclasses, the process of executing individual functions can be simplified. The ultimate goal of SPACE Next Gen is to create a unified SPACE code that can model the electrical power systems of the ISS, Orion MPCV, and future space power projects. The unified code will be organized into modules that allow for new hardware and calculation models to be added or modified without affecting the overall framework of the code. SPACE has grown in the decades since its initial release and continues to grow through the efforts of the SPACE Next Gen team. In this manner, SPACE remains in a position to effectively address the electrical power systems on future NASA space missions.

\section{Conclusion}

SPACE has had a long and robust use at NASA GRC in support of some of NASA's most prestigious human spaceflight programs. The code routinely performs critical analyses, such as the CoFR analyses conducted for each visiting vehicle mission to the ISS and the essential code-to-code validation that helped define the Orion EPS design. Results of SPACE analyses have prompted numerous design and operational changes that have yielded resource savings and increased performance. The Lithium-Ion battery model, solar array enhancements model, and other recent code improvements discussed in this paper ensure the continued relevance of SPACE for existing and future spaceflight missions. Looking ahead, we expect that SPACE will continue to have an instrumental role in the support of future NASA projects, such as a lunar-orbiting outpost and missions to Mars. 


\section{Acknowledgments}

The authors wish to acknowledge Sarah Tipler, Jeff Hojnicki, Tom Kerslake, David Hoffman, and other members of the Space Power Architecture and Analysis group at NASA GRC for their contributions to SPACE analyses and code development as well as their feedback and editorial comments on early drafts of this paper.

The authors also wish to acknowledge the Boeing Spacecraft Time-phased Electrical Loads Analysis and Resources (STELAR) team and the many personnel in the International Space Station Program Office who have supported SPACE analyses. Their combined inputs and support have been critical in all past SPACE assessments. 


\section{References}

${ }^{1}$ Hojnicki, J. S., Green, R. D., Kerslake, T. W., McKissock, D. B., and Trudell, J. J., "Space Station Freedom Electrical Performance Model," NASA TM 1993-106395, $28^{\text {th }}$ Intersociety Energy Conversion Engineering Conference, Atlanta, Georgia, August 8-13, 1993.

${ }^{2}$ Kerslake, T. W., Hojnicki, J. S., Green, R. D., and Follo, J. C., "System Performance Predictions for Space Station Freedom's Electric Power System," NASA TM 1993-106396, 28 ${ }^{\text {th }}$ Intersociety Energy Conversion Engineering Conference, Atlanta, Georgia, August 8-13, 1993.

${ }^{3}$ Kerslake, T. W., Scheiman, D. A., and Hoffman, D. J., "Pre-Flight Dark Forward Electrical Testing of the Mir Cooperative Solar Array," NASA TM 1997-107496, 32 nd Intersociety Energy Conversion Engineering Conference, Honolulu, Hawaii, July 27August 1, 1997.

${ }^{4}$ Kerslake, T. W., and Hoffman, D. J., "Mir Coorporative Solar Array Flight Performance Data and Computational Analysis," $32^{\text {nd }}$ Intersociety Energy Conversion Engineering Conference, Honolulu, Hawaii, July 27-August 1, 1997.

${ }^{5}$ Kerslake, T. W., and Hoffman, D. J., "Performance of the MIR Cooperative Solar Array After 2.5 Years in Orbit," NASA TM 1999-209287, 34 ${ }^{\text {th }}$ Intersociety Energy Conversion Engineering Conference, Vancouver, British Columbia, Canada, August $1-5,1999$.

${ }^{6}$ Kerslake, T. W., Haraburda, F. M., Riehl, J. P., "Solar Power System Options for the Radiation and Technology Demonstration Spacecraft," NASA TM 2000-210243, 35 ${ }^{\text {th }}$ Intersociety Energy Conversion Engineering Conference, Las Vegas, Nevada, July 24-28, 2000.

${ }^{7}$ Kerslake, T. W., and Gefert, L. P., "Solar Power Analyses for Electric Propulsion Missions," NASA TM 1999-209289, 34th Intersociety Energy Conversion Engineering Conference, Vancouver, British Columbia, Canada, August 1-5, 1999.

${ }^{8}$ Gurrisi, C., Seidel, R., Dickerson, S., Didziulis, S., Frantz, P., and Ferguson, K., "Space Station Control Moment Gyroscope Lessons Learned," NASA CP-2010-216272, 40 ${ }^{\text {th }}$ Aerospace Mechanisms Symposium, NASA Kennedy Space Center, May 12-14, 2010.

${ }^{9}$ Dalton, P., North, T., Bowens, E., and Balcer, S., "International Space Station Lithium-Ion Battery Start-Up," 35 ${ }^{\text {th }}$ Space Power Workshop, Manhattan Beach, CA, April 24-27 2017.

${ }^{10}$ Dalton, P. and Cohen, F., "Li-ion Battery for ISS," Space Power Workshop, Manhattan Beach, CA, April 2004.

11“Lithium Ion Cells For Satellites - Power Optimized," LSE51, 102 \& 134 datasheet, GS Yuasa Lithium Power, Inc.

${ }^{12}$ Dalton, P. J., and North, T., "International Space Station Lithium-Ion Main Battery Thermal Runaway Propogation Test,” NASA Battery Workshop, November 14-16, 2017.

${ }^{13}$ Fincannon, J., "Comparison of ISS Power Telemetry With Analytically Derived Data for Shadowed Cases," NASA TM 2002211715, 37 $7^{\text {th }}$ Intersociety Energy Conversion Engineering Conference, Washington, DC, July 28-August 2, 2002.

${ }^{14}$ Barry, R. G., and Chorley, R.J., Atmosphere, Weather, and Climate, $8^{\text {th }}$ ed., New York, NY: Routledge, 2003.

${ }^{15}$ Stephens, G. L. et al., "The Albedo of Earth," Review of Geophysics, Vol. 53, 2015.

${ }^{16}$ Gourdeau, J., "Albedos of Different Clouds," Le Laboratoire de Météorologie Physique, Clermont-Ferrand, France, 2004

${ }^{17}$ Jannette, A. G., Fincannon, H. J., Hojnicki, J. S., Kerslake, T. W., McKissock, D. B., and Rodriguez, C. D., "Validation of International Space Station Electrical Performance Model via On-Orbit Telemetry," $37^{\text {th }}$ Intersociety Energy Conversion Engineering Conference, Washington, DC, July 28-August 1, 2002.

${ }^{18}$ Delleur, A. M., and Kerslake, T. W., "Electrical Performance of the International Space Station US Photovoltaic Array During Bifacial Illumination," $37^{\text {th }}$ Intersociety Energy Conversion Engineering Conference, Washington, DC, July 28-August 1, 2002.

${ }^{19}$ Berthe, P., Over, A., Picardo, M., and Byers, A., "Orion European Service Module (ESM) development, integration and qualification status,” AIAA Space 2017, Orlando, Florida, 2017. http://hdl.handle.net/2060/20170009574

${ }^{20}$ Wilde, D., Schubert, K., Grantier, J., Deloo, P., Price, L., Fenoglio, F., and Chavy, S., "Building Transatlantic Partnerships in Space Exploration: The MPCV-SM Study," Global Space Exploration Conference; May 22-24, 2012; Washington, D.C. http://hdl.handle.net/2060/20120012885

${ }^{21}$ Hughes, B., Bradley, K., and Johnson, S., “CEV / Orion Power System Architecture," Space Power Workshop; Los Angeles, CA April 24-26, 2007.

${ }^{22}$ Bury, K., and Kerslake, T., "The Effect of Reaction Control System Thruster Plume Impingement on Orion Service Module Solar Array Power Production," NASA TM 2008-215423, Sixth International Energy Conversion Engineering Conference, Cleveland, Ohio, July 28-30, 2008. 